\title{
LOS DESACUERDOS EN EL DERECHO *
}

\author{
Lorena Ramírez Ludeña \\ Universidad Pompeu Fabra
}

RESUMEN. En este trabajo me propongo abordar el problema de los desacuerdos en el derecho, inicialmente planteado por R. DWORKIN contra el positivismo de corte hartiano. Expondré primero los principales argumentos que han aparecido en el debate. Distinguiré después diferentes niveles en que puede haber desacuerdos entre los juristas y, tomándolos en consideración, articularé una respuesta pluralista a la crítica dworkiniana, que pretende mostrar que está lejos de socavar las tesis positivistas básicas. Asimismo, defenderé la incidencia de las nuevas teorías de la referencia en la respuesta positivista al problema de los desacuerdos. Para ello, argumentaré que el carácter convencional del derecho no está necesariamente vinculado con el carácter convencional del lenguaje del derecho. Las nuevas teorías de la referencia asumen que tenemos un conocimiento deficiente de los objetos a los que, no obstante, somos capaces de referir. Los desacuerdos pueden entonces tener sentido en tanto intentos en conflicto por determinar los rasgos centrales, o la naturaleza, del objeto de discusión.

Palabras clave: desacuerdos jurídicos, DwORKIN, positivismo jurídico, nuevas teorías de la referencia.

ABSTRACT. In this paper I analyze the problem of legal disagreements, initially raised by R. DwORKIN against hartian positivism. Firstly, I present the main arguments in the debate. Then, I distinguish different levels in which lawyers might disagree and, taking them into consideration, I articulate a pluralist answer to the dworkinian challenge that shows that the fundamental positivist tenets remain untouched. Moreover, I defend the significance of the new theories of reference in the positivist answer to the problem of legal disagreements. In this sense, I argue that the conventional character of law is not necessarily connected with the conventional character of legal language. The new theories of reference assume that we have a deficient knowledge of the objects to which, notwithstanding, we are able to refer. So, disagreements might make sense as conflicting attempts to determine the central features, or the nature, of the object under discussion.

Keywords: legal disagreements, Dworkin, Legal Positivism, New Theories of Reference.

* Fecha de recepción: 3 de octubre de 2012. Fecha de aceptación: 13 de noviembre de 2012. 


\section{INTRODUCCIÓN}

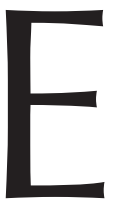

xisten intuiciones extendidas y hechos que difícilmente pueden controvertirse acerca del fenómeno jurídico. Por un lado, suele aceptarse comúnmente que, para que exista un sistema jurídico, deben tener lugar ciertos hechos sociales ${ }^{1}$. Estos pueden cambiar, variando al mismo tiempo el derecho. Muchas han sido las propuestas que se han ofrecido para caracterizar los hechos sociales relevantes. En el modelo defendido por HART, el derecho depende de la convergencia en la conducta y las actitudes de determinados sujetos. Concretamente, los funcionarios públicos desarrollan una actitud crítico-reflexiva en relación con el patrón de conducta que mayoritariamente siguen al identificar el derecho ${ }^{2}$. Al mismo tiempo, también es difícil cuestionar que a menudo se desacuerda sobre cuál es el derecho. A pesar de ello, el derecho parece regir nuestra conducta de un modo razonable.

¿De qué modo pueden conciliarse las distintas consideraciones anteriores? ¿Cómo es posible que el derecho rija nuestra conducta si los desacuerdos son frecuentes? ¿Puede afirmarse que el derecho depende de la existencia de convergencia, al mismo tiempo que se sostiene que a menudo existe controversia acerca de lo que establece? La disputa en torno a la problemática de los desacuerdos entre DwORKIN y los positivistas precisamente deja constancia de las dificultades que enfrentan estos últimos al tratar de salvaguardar el carácter convencional del derecho aun cuando los operadores jurídicos discuten - al menos en apariencia- sobre lo que el derecho prevé ${ }^{3}$. Esto es, mientras que el positivismo enfatiza el elemento convencional del derecho al destacar la relevancia de la convergencia en la conducta y las actitudes de determinados sujetos, DWORKIN pone el énfasis en su naturaleza controvertida, que atenta contra la idea de convergencia característicamente positivista. La problemática para el positivismo se ve acentuada puesto que, de acuerdo con su propia reconstrucción, las creencias y acti-

1 Esto sería aceptado con carácter general por los autores no-positivistas, que también admiten que ciertos hechos sociales son relevantes.

2 HART (1994: 103 y ss.), añade, como segunda condición para la existencia de los sistemas jurídicos, la eficacia general de las reglas identificadas por la regla de reconocimiento.

3 Resulta controvertido determinar en qué medida el positivismo se compromete con un modelo convencionalista acerca del derecho. De acuerdo con una caracterización estándar del modelo positivista, la existencia del derecho depende de que acontezcan determinados hechos sociales que son contingentes. Pero no todos aquellos que sostienen la relevancia de ciertos hechos sociales contingentes pueden ser considerados convencionalistas. En particular, me centraré en aquellas concepciones que afirman que el derecho depende de la convergencia de determinadas conductas y actitudes. En este ámbito, uno de los aspectos principales de discusión es qué tipo de vinculación debe existir entre las creencias y actitudes de los diferentes individuos. Así, en ocasiones se llama «convencionalistas» a quienes entienden que las razones para adoptar un estándar dependen, al menos en parte, del hecho de que los demás también lo adopten. En este trabajo no me comprometeré con una visión convencionalista acerca del derecho como ésta, sino que me limitaré a considerar qué problemas supone el hecho de que en la práctica jurídica los desacuerdos sean frecuentes para la noción de convergencia que subyace a las diferentes posiciones positivistas de corte hartiano. Emplearé los términos «acuerdo»y «desacuerdo» en un sentido laxo, sin comprometerme tampoco con el carácter explícito que frecuentemente se asocia con esas nociones. Y, aunque a efectos expositivos adoptaré el positivismo de HART y la regla de reconocimiento como elementos de referencia, entenderé que los criterios de identificación del derecho son convencionales sin asumir que se expresan en una regla de reconocimiento que impone a los funcionarios el deber de aplicar las normas que identifica. Acerca del carácter convencional del derecho, vid. MARMOR, 2009, y VILAJOSANA, 2010. 
tudes de los participantes en la práctica jurídica deben ser tomadas en cuenta. Entre ellas destaca el hecho de que los participantes parecen discutir con sentido acerca de lo que el derecho establece. No obstante, conforme al modelo positivista, si el derecho depende de la convergencia, el propio desacuerdo muestra que no hay derecho. Por ello, los desacuerdos en casos controvertidos carecerían de sentido.

En este trabajo me propongo analizar los méritos de esta crítica al positivismo. Expondré primero los argumentos centrales que se han ofrecido en el debate sobre la cuestión. Distinguiré después diferentes niveles en que los juristas desacuerdan para terminar ofreciendo una respuesta pluralista al desafío dworkiniano.

\section{EL DEBATE HART-DWORKIN}

La disputa entre HART y DWORKIN transcurre durante un largo periodo de tiempo, con la intervención de numerosos autores, que desacuerdan incluso sobre el propio objeto de controversia. El debate filosófico ha sido cambiante y múltiple. Sin embargo, no cabe duda de que el problema relativo a cómo abordar los desacuerdos en el derecho ha ocupado un lugar central en la discusión entre positivistas y dworkinianos. En ocasiones se ha señalado que el problema de los desacuerdos no tiene la incidencia que DwORKIN y sus seguidores pretendían. Otras veces se ha considerado que este problema, a diferencia de las primeras críticas dworkinianas, sí supone un importante desafío para el positivismo ${ }^{4}$. Considero que se trata de una crítica de gran trascendencia, a la que debe ofrecerse una respuesta; no obstante, creo que el desafío planteado por DWORKIN no ha cambiado, aunque lo han hecho las explicaciones que ha dado de por qué el positivismo no puede ofrecer una caracterización adecuada de los casos difíciles, en los que los juristas desacuerdan. Así, en un primer momento DwORKIN destacó la imposibilidad del positivismo para dar cabida a los principios y al papel que estos desempeñan en los casos difíciles. Posteriormente, su crítica se concentró en el carácter convencional del modelo positivista, que no permite ofrecer una reconstrucción adecuada de la práctica jurídica en tanto práctica argumentativa. En cualquier caso, la dificultad del positivismo para dar cuenta de los casos controvertidos es una crítica recurrente desde los primeros escritos de DWORKIN ${ }^{5}$.

En sus planteamientos iniciales en Los derechos en serio (1977), DwORKIN señala que, si observamos lo que ocurre en los tribunales, puede constatarse el papel fundamental de los principios en las discusiones acerca de los derechos y las obligaciones jurídicas. A partir de casos extraídos de la jurisprudencia estadounidense, DwORKIN sostiene que no sólo las reglas sino también los principios forman parte del derecho y determinan los derechos y obligaciones de las partes en el proceso ${ }^{6}$. Los positivistas,

${ }^{4}$ Aunque SHAPIRO (2007) y LeITER (2007), dos de los autores de referencia que han abordado la cuestión, coinciden en que se trata de un nuevo desafío planteado por DWORKIN, LEITER considera que no representa un serio problema para el positivismo.

5 El propio DwORKIN (2006: 254 y ss.), ha señalado que su proyecto contra el positivismo constituye una suerte de continuo.

6 Para Dworkin (1977: 100), «existe una obligación jurídica siempre que las razones que fundamentan tal obligación, en función de diferentes clases de principios jurídicos obligatorios, son más fuertes que las razones o argumentos contrarios». 
que asumen que las normas jurídicas son identificadas a partir de criterios relacionados con su pedigrí, no pueden dar cabida a los principios, puesto que el rol que estos desempeñan depende de consideraciones sustantivas. Conforme al modelo positivista, la existencia de una obligación jurídica depende de que el caso esté comprendido en una regla que es válida porque satisface determinados criterios que se vinculan con su origen (fue creada por una determinada autoridad, siguiendo determinados procedimientos, etc.) y no con su contenido. En ausencia de regla, tal obligación jurídica no existe y el juez ejerce su discreción ${ }^{7}$. Los principios no pueden entonces formar parte del derecho en el esquema positivista puesto que no contamos con ninguna fórmula para identificarlos ${ }^{8}$. Ello es así dado que, aunque suela defenderse la incidencia de un determinado principio destacando su impacto en las actuaciones de las instituciones jurídicas, los principios no tienen con tales actos una conexión lo bastante simple y directa como para que pueda afirmarse que son identificados conforme a los criterios especificados por la regla de reconocimiento.

En contraste con lo anterior, de acuerdo con DwORKIN los individuos tienen derechos que no dependen de su reconocimiento explícito por parte de los sistemas jurídicos y es deber del juez garantizarlos también en los casos difíciles, en lugar de crear retroactivamente nuevos derechos ${ }^{9}$. El juez debe determinar quién tiene derecho a ganar el caso empleando argumentos basados en principios, que justifican una decisión si muestran que ésta respeta o asegura algún derecho, y que dependen por tanto de consideraciones sustantivas ${ }^{10}$.

7 DwORKIN, 1977: 66 y ss. Según DwORKIN (1977: 83 y ss.), muchos de estos supuestos eran reconstruidos por los positivistas como casos de discreción en sentido fuerte, que podría ser definida como la posibilidad de elección entre distintos cursos de acción igualmente admisibles. Acerca de los diferentes sentidos del término «discreción», vid. IGLESIAS, 1999: 24 y ss.

8 De acuerdo con DwORKIN (1977: 72 y ss.), los principios, a diferencia de las reglas, son pautas no concluyentes que entran frecuentemente en conflicto. Estos conflictos se resuelven mediante el mecanismo de la ponderación.

9 Según Dworkin (1977: 40), defender que no hay derechos cuando el caso es difícil presupone una teoría filosófica general, desde su punto de vista muy discutible, de acuerdo con la cual ninguna proposición puede ser verdadera salvo que exista algún procedimiento para demostrar su verdad. DwORKIN (1977: 36) no asume que los derechos tienen un carácter metafísico especial, sino que defiende que son triunfos políticos en manos de los individuos, que tienen tales derechos cuando una meta colectiva no justifica negarles lo que desean tener o hacer en tanto individuos, o cuando no es justificación para imponerles alguna pérdida o perjuicio.

10 DwORKIN, 1977: 146 y ss. Las afirmaciones de DWORKIN sobre el papel de los principios en el razonamiento jurídico dieron lugar a un debate en torno a las diferencias de estos con las reglas y a si la regla de reconocimiento hartiana podía darles cabida. La discusión se extendió también a la cuestión de la compatibilidad de los postulados básicos del positivismo con la incorporación de la moral en el derecho. Se trata del conocido debate, en el seno del positivismo, entre positivistas incluyentes y excluyentes. Mientras que los primeros defienden que la regla de reconocimiento puede contingentemente incorporar la moral entre las condiciones de validez jurídica, este extremo es negado por los positivistas excluyentes, quienes sostienen que la caracterización adecuada de tales supuestos requiere admitir que, para resolver estos casos, debe recurrirse a estándares extrajurídicos. En otras palabras, el positivismo excluyente se compromete con la conocida tesis de las fuentes, según la cual ninguna norma es jurídica si no cuenta con una fuente social. RAZ introdujo primero esta tesis en The Authority of law (1979) y la defendió especialmente en Authority, law and morality (1985), recogido posteriormente en Ethics in the public domain (1994). Para una defensa del positivismo jurídico inclusivo, WALUCHOW (1994), COLEMAN (2001) y MORESO (2001). Como principales exponentes del positivismo jurídico excluyente, vid. RAZ (1979 y 1994) y SHAPIRO (1998a, 1998b y 2011). Considero que, así entendidos, estos debates en el seno del positivismo no responden al desafío central de DwORKIN. Los positivistas incluyentes y excluyentes toman en consideración el carácter controvertido de la moral. Sin embargo, no ofrecen una respuesta adecuada para los supuestos verdaderamente problemáticos, en que la propia incorporación o remisión a la moral se pone en duda. El positivismo tiene dificultades para reconstruir adecuadamente lo que 
Años más tarde, DwORKIN desarrolló muchas de las ideas anteriores en Law's Empire (1986), enfatizando el carácter argumentativo de la práctica jurídica. Esto es, los juristas discuten habitualmente acerca de lo que el derecho requiere y defienden sus posiciones ofreciendo razones ${ }^{11}$. Concretamente, de acuerdo con DwORKIN la argumentación jurídica tiene un carácter creativo y constructivo. Por un lado, y del mismo modo que ocurre, por ejemplo, en el caso del arte, el derecho supone un ejercicio de interpretación creativa, en el cual se pretende interpretar algo creado por los individuos como una entidad distinta de ellos. En este sentido, determinar en qué consiste la práctica y qué requiere es algo diferente de determinar qué creen sus participantes. El razonamiento jurídico es además un ejercicio de interpretación constructiva, lo que significa que el derecho consiste en la mejor justificación de nuestras prácticas consideradas como un todo. La interpretación constructiva supone adscribir un propósito a un objeto o práctica para hacerlo el mejor ejemplo posible del tipo o género al que pertenece. Conforme a lo señalado por DWORKIN, atribuimos un propósito a la práctica a la luz del cual se determinan sus exigencias. Sin embargo, no todo tiene cabida, puesto que la historia o la manera en que la práctica u objeto se ha desarrollado restringe las interpretaciones disponibles ${ }^{12}$. En este sentido, el mejor propósito es el que muestra la práctica a su mejor luz, equilibrando el respeto por la historia de la práctica y su justificación. En particular, el propósito del derecho es, según DWORKIN, el ejercicio justificado de la coerción estatal, tomando en consideración los derechos y responsabilidades de los individuos que derivan de las decisiones políticas del pasado ${ }^{13}$.

Los desacuerdos que dejan constancia del carácter argumentativo del derecho no se limitan a disputas generales acerca de si la moral constituye o no un criterio de validez jurídica, o al rol desempeñado por los principios en el razonamiento jurídico, sino que se ponen también de manifiesto cuando se discute lo que establece el derecho en un sistema jurídico particular invocando diferentes modos de interpretar las disposiciones. Pero, ¿por qué el positivismo no puede ofrecer una reconstrucción adecuada de tales supuestos? Conforme a lo señalado por DwORKIN en esta segunda etapa, el problema es que para los positivistas el derecho es una cuestión de hechos históricos (esto es, de acuerdo con la terminología empleada por DwORKIN se comprometen con la llamada plain fact view), en relación por ejemplo, a lo que el legislador o los tribunales han decidido en el pasado ${ }^{14}$. Es decir, la verdad de las proposiciones jurídicas - de las afirmaciones con respecto a lo que un sistema jurídico establece para un determinado supuesto o grupo de supuestos- depende de ciertos hechos históricos que

ocurre en estos casos, que dejan constancia de la ausencia de una práctica social uniforme relativa a la identificación del derecho.

${ }^{11}$ Según Dworkin (1986: 13), cada actor entiende que lo que el derecho establece depende de la verdad de ciertas proposiciones que sólo tienen sentido en el marco de la práctica.

12 DwORKIN, 1986: 45 y ss. DwORKIN (1986: 66 y ss.) distingue tres estadios, que no suelen diferenciarse claramente en la práctica: el pre-interpretativo, el interpretativo y el post-interpretativo. Acerca de las etapas de la interpretación constructiva, vid. IGLESIAS, 1999: 142-145.

${ }^{13}$ DwORKIN, 1986: 93. A partir de este concepto pueden elaborarse diferentes concepciones que muestren la práctica a su mejor luz. Aunque no me detendré por el momento en esta cuestión, DwORKIN (1986: 176 y ss.) defiende, tras analizar el convencionalismo y el pragmatismo, el derecho como integridad. Sobre esta cuestión, IGLESIAS, 1999: 148 y ss.

${ }^{14}$ DwORKIN, 1986: 7 y ss. 
constituyen los fundamentos (grounds) del derecho ${ }^{15}$. Entonces, según DWORKIN, el positivismo podría dar cuenta de los desacuerdos empíricos, sobre si se han producido ciertos hechos en el pasado, pero no podría reconocer controversias acerca de qué elementos son jurídicamente relevantes. Así, no pueden ofrecer una caracterización adecuada de los llamados «desacuerdos teóricos», y deben entender que en realidad se trata de desacuerdos acerca de cómo debe ser el derecho, en lugar de acerca de sus fundamentos ${ }^{16}$.

De acuerdo con lo señalado por DWORKIN, frecuentemente se niega la posibilidad de que existan desacuerdos teóricos porque se suscriben teorías semánticas acerca del derecho. Las teorías semánticas sostienen que el significado de las palabras depende de criterios compartidos. En el caso del derecho, esto supone asumir que los juristas usan los mismos criterios al decidir si las proposiciones jurídicas son verdaderas o falsas. Así, conforme a la reconstrucción dworkiniana del positivismo, el propio significado de la palabra «derecho» hace que el derecho dependa de criterios compartidos y que el acuerdo en los fundamentos del derecho sea determinante ${ }^{17}$. Este es el conocido argumento del aguijón semántico, que es introducido para explicar por qué los positivistas requieren que los criterios que empleamos para determinar cuándo las proposiciones jurídicas son verdaderas se establezcan por consenso ${ }^{18}$.

\section{RESPUESTAS AL PROBLEMA}

A continuación analizaré diferentes respuestas que se han ofrecido al problema de los desacuerdos. Antes, no obstante, abordaré brevemente la crítica de DWORKIN que destaca que el positivismo es una teoría semántica.

\subsection{La crítica del aguijón semántico}

Como hemos visto, según DwORKIN el positivismo no puede ofrecer una caracterización adecuada de los desacuerdos porque defiende una teoría semántica conforme a la cual los individuos comparten criterios para la aplicación del término «de-

15 En mi reconstrucción, emplearé el término «fundamentos» en lugar de, por ejemplo, «criterios de identificación» o «fuentes», precisamente porque, como trataré de mostrar, los desacuerdos destacados por DWORKIN versan sobre cuestiones diversas: en ocasiones, sobre los criterios, otras acerca de las fuentes, a veces sobre cuestiones interpretativas, etcétera.

16 Los desacuerdos teóricos suponen diferentes reconstrucciones sobre lo que determina la verdad de las proposiciones jurídicas. Los desacuerdos empíricos, en cambio, asumen un acuerdo sobre los elementos determinantes, pero cuestionan si estos se han instanciado. En opinión de STAVRopoulos (1996: 125), los desacuerdos teóricos o sustantivos son acerca de si algo es X, lo que desemboca en diferentes perspectivas respecto de cuándo algo es $\mathrm{X}$.

17 DwORKIN, 1986: 31-37. Adviértase que, de acuerdo con DwORKIN, este no es un problema que afecte exclusivamente a HART, sino que también cabe reconstruir de este modo a positivistas como AUSTIN, a los defensores del derecho natural y a los realistas. Así, puede considerarse que todos ellos intentan dilucidar los criterios compartidos por los juristas para considerar que algo es o no derecho, y en este sentido serían también teorías semánticas.

18 DwORKIN, 1986: 33. Aunque DwORKIN señala en su trabajo que el positivismo ha sido picado por el aguijón semántico, generalmente se utiliza la expresión para referir a la propia crítica de DwORKIN. 
recho», o, lo que considera lo mismo, criterios para decidir cuándo una proposición jurídica es verdadera. Esto supone que los sujetos coinciden, si son competentes en el uso del término, en cuáles son los fundamentos del derecho. Cuestionarlos carecería de sentido puesto que conllevaría cuestionar los propios criterios de aplicación del término.

Entonces, si el propio significado de la palabra «derecho» hace que el derecho dependa de criterios compartidos, el positivismo estaría comprometido con asumir que las discusiones sobre los fundamentos del derecho constituyen disputas meramente verbales. Las controversias en este ámbito carecerían de sentido porque los sujetos estarían empleando el mismo término con distintos significados, sin que exista por tanto un desacuerdo genuino ${ }^{19}$.

Si atendemos a los trabajos de HART, la crítica de DwORKIN genera cierta perplejidad: HART no pretende proporcionar una definición de «derecho», sino un análisis del concepto de derecho ${ }^{20}$, y manifiesta expresamente su rechazo de semánticas que vinculan los términos con condiciones necesarias y suficientes ${ }^{21}$. Y, aunque sostuvo que en la base de todo sistema jurídico existe una regla de reconocimiento que especifica los criterios para la identificación del derecho, aclaró de manera expresa que no es parte del significado del término «derecho» que tal regla esté presente en todos los sistemas $^{22}$.

La crítica de DwORKIN puede ser cuestionada a partir, fundamentalmente, de dos grupos de argumentos: i) en su reconstrucción, DWORKIN asocia el modelo positivista hartiano con un modelo semántico criteriológico, pero no hay elementos en la obra del propio HART que nos conduzcan a tal conclusión y, lo que es más importante, hay modelos alternativos más plausibles que el que DwORKIN atribuye al positivismo, y compatibles con el mismo; ii) con independencia de que se sostenga o no el modelo criteriológico, puede cuestionarse la vinculación entre la posición semántica —en sentido estricto, la posición metasemántica ${ }^{23}$ - con respecto al término «derecho» y los criterios para determinar el valor de verdad de las proposiciones jurídicas. Precisamente por ello, puede haber desacuerdo acerca de una de las cuestiones sin que lo haya en relación con la otra.

19 La cuestión no es sólo que en las disputas los términos deben emplearse con el mismo significado para que éstas tengan sentido, sino que además, si las condiciones de aplicación determinan el objeto de controversia, los sujetos estarían discutiendo acerca de cosas distintas. DwORKIN (1986: 37 y ss.) considera que el positivismo se halla en una encrucijada: o sostiene que los desacuerdos recaen sobre casos marginales de aplicación del término, en cuyo caso deberían comprometerse con que carecen de relevancia, o bien recaen sobre aspectos centrales, y entonces las controversias son sólo aparentes porque los sujetos emplean el mismo término con distintos significados.

20 HART, 1994: 81. En este mismo sentido, vid. SHAPIRO, 2011: cap. 1.

21 HART, 1994: 15. En realidad, sorprendentemente DWORKIN no afirma que el positivismo busque proporcionar una definición del término, sino que es mejor reconstruirlo como una teoría acerca del término «derecho», puesto que es lo que más sentido da a su posición. En contraste con lo anterior, ENDICOTT (2001: 46) señala que la mejor reconstrucción de aquellos supuestos en que HART parece apelar a condiciones necesarias y suficientes consiste en entender que se está limitando a destacar los rasgos prominentes de los casos paradigmáticos de derecho.

22 HART, 1994: 246.

23 Esto es, el debate en relación a si el positivismo adhiere o no el modelo criteriológico es un debate metasemántico, acerca de cómo se determina el contenido semántico de los términos y expresiones, que se halla en un nivel distinto de las posiciones específicas con respecto a cuál es el significado del término «derecho». 
Si atendemos a la primera de las cuestiones, la crítica de DWORKIN parece fácilmente rebatible: las distintas concepciones positivistas no extraen sus conclusiones a partir del análisis del significado del término «derecho», sino que teorizan acerca de su naturaleza. Esta teorización se lleva a cabo con frecuencia a partir del análisis del concepto de derecho ${ }^{24}$. No obstante, aun si admitiéramos que el positivismo está preocupado por el análisis del término «derecho», resulta criticable que DwORKIN le atribuya el modelo criteriológico simple. Dicho modelo asume que vinculamos una serie de descripciones con los términos, que nos son transparentes, y que determinan los objetos a los que se aplican. Es este un modelo demasiado exigente con el conocimiento individualizador de los sujetos — que generalmente es muy pobre y con frecuencia está equivocado- y que, en lo que aquí interesa, no puede dar sentido a los desacuerdos, puesto que los sujetos estarían asociando el mismo término con distintas descripciones, que referirían a diferentes objetos. Existen en cambio modelos mucho más plausibles, y actualmente bastante extendidos, que se oponen frontalmente al modelo criteriológico ${ }^{25}$. Precisamente por ello puede rechazarse la crítica de DwORKIN, que plantea la cuestión a modo de disyuntiva entre el modelo criteriológico y la metodología interpretativa que él defiende: existen otras opciones y él ha atribuido al positivismo la menos plausible, que reconstruye adecuadamente un número muy limitado de términos.

Pero, incluso si aceptáramos que el modelo positivista se centra en el análisis del término «derecho», y admitiéramos además que adhiere al modelo criteriológico, considero que la crítica de DwORKIN es infundada. Así, DworKIN establece un vínculo entre la posición que el positivismo supuestamente sostiene con respecto al término «derecho»y los elementos que determinan el valor de verdad de las proposiciones jurídicas de sistemas jurídicos específicos. Tal vinculación es sin embargo muy cuestionable: determinar cuál es el significado del término «derecho» parece algo distinto de determinar cuáles son los fundamentos del derecho de un sistema jurídico particular. Y, si nos centramos específicamente en el problema de los desacuerdos, puede haber desacuerdo acerca de los criterios que fijan la extensión de la palabra «derecho» sin que lo haya acerca de los fundamentos del derecho, y a la inversa. Por ejemplo, la práctica lingüística en España podría coincidir en considerar que el término «derecho» significa, tal como establece la Real Academia Española, «conjunto de principios y normas, expresivos de una idea de justicia y de orden, que regulan las relaciones humanas en toda sociedad y cuya observancia puede ser impuesta de manera coactiva», y, sin embargo, desacordar acerca de los fundamentos que determinan el valor de verdad de las proposiciones jurídicas del sistema español. También es posible que ocurra lo contrario: que exista un amplio consenso sobre los fundamentos, pese a que se desacuerde sobre si la definición de la Real Academia captura adecuadamente nuestras prácticas lingüísticas ${ }^{26}$.

24 Recientemente, SHAPIRO ha elaborado un enérgico argumento para mostrar de qué manera el análisis conceptual ilumina la naturaleza del derecho. Vid. SHAPIRO, 2011: 7 y ss. Por su parte, RAZ (2001: 1-37) diferencia también las preguntas por el significado de un término y las relativas al concepto — que no requieren que tengamos un término- y argumenta que HART se centra en la segunda de estas cuestiones.

25 Así, tanto el modelo según el cual contamos con una familia de descripciones, como así también el de las nuevas teorías de la referencia, pueden dar cabida a disputas acerca del significado de los términos. Con respecto a la relevancia de la familia de descripciones, vid. SEARLE, 1958, y STRAWSON, 1959. Como partidarios de las nuevas teorías de la referencia, vid. DonnEllan, 1970; KRIPKE, 1971 y 1980, y PuTNAM, 1973 y 1975.

26 Sobre esta cuestión, vid. ColEMAN-SiMCHEN (2003: 8). Consideremos, en cambio, que los positivistas tratan de capturar los aspectos centrales de la práctica jurídica y que generalmente lo hacen sirviéndose del 
La crítica del aguijón semántico no representa, por tanto, un problema para el positivista. Este no extrae sus conclusiones sobre la relevancia de la convergencia de su adopción de una determinada semántica. Pese a ello, la convergencia en los criterios que determinan el valor de verdad de las proposiciones jurídicas es central para el positivista. Así, fruto de su análisis conceptual, el positivista concluye que la convergencia es relevante, pero ello no se sigue de defender que los conceptos requieren de criterios compartidos, sino de que forma parte de la mejor explicación del fenómeno jurídico. En otras palabras, la convergencia no es relevante por el tipo de concepto que es el concepto de derecho, sino porque el resultado del análisis conceptual así lo determina.

Resta entonces analizar la crítica consistente en que el modelo positivista, que requiere de la idea de convergencia, no permite ofrecer una caracterización adecuada de los desacuerdos en los criterios de identificación del derecho, las fuentes y su interpretación.

\subsection{Problemas persistentes. Tres respuestas}

Si tomamos en consideración la práctica jurídica, tal y como esta se presenta, los sujetos parecen desacordar sobre lo que establece el derecho. No desacuerdan acerca de cuestiones empíricas - por ejemplo, si el Parlamento aprobó una determinada ley-. Y tampoco parecen discutir acerca de cómo deben resolverse los casos cuando el derecho no establece una solución normativa o cuando la respuesta que establece les parece injusta. El positivismo, que hace de la convergencia un elemento determinante, parece incapaz de reconstruir adecuadamente esos casos puesto que la propia

análisis del concepto de derecho. Bajo una lectura más plausible de la crítica de Dworkin, ésta denunciaría que los positivistas entienden que los sujetos comparten el concepto que ellos tratan de dilucidar, y que compartir un concepto requiere compartir los criterios de aplicación del mismo, lo que en el caso del derecho conllevaría la necesidad de convergencia con respecto a los fundamentos del derecho de los sistemas jurídicos particulares. Esto supone atribuir al positivismo tres tesis muy problemáticas: $a$ ) su análisis conceptual se basa en la identificación de los criterios de aplicación transparentes del concepto que comparten los sujetos; $b$ ) los sujetos no pueden discutir acerca de los criterios que comparten, y c) los criterios de aplicación del concepto de derecho son los criterios que emplean los juristas para determinar el valor de verdad de las proposiciones relativas a sistemas particulares. Aunque pueda resultar controvertido en sus detalles, el análisis conceptual que llevan a cabo los positivistas no se basa en la elucidación de los criterios compartidos en relación con el concepto de derecho. Si fuera así, su labor no sería muy distinta de la del análisis lingüístico. Los positivistas tratan de iluminar los aspectos centrales del fenómeno jurídico, tomando en cuenta verdades evidentes relativas al derecho y elaborando teorías que les den cabida en una suerte de equilibrio reflexivo. En este sentido, vid. SHAPIRO, 2011: 13 y ss. Asimismo, RAz (2001: 6 y ss.) defiende que una buena explicación del concepto no tiene que comprometerse con establecer condiciones necesarias y suficientes para su aplicación, sino que supone frecuentemente destacar aspectos que no son distintivos del fenómeno, condiciones que son derrotables, exige también ofrecer una reconstrucción adecuada de su vínculo con otros conceptos, etc. Además, aun asumiendo la relevancia de los criterios compartidos, resulta plausible que los sujetos discutan acerca de ellos si tomamos en consideración aspectos como el carácter opaco y no individualista de dichos criterios. Así lo ha señalado RAz, 2001: 14 y ss. De hecho, es frecuente afirmar que un sujeto ha adquirido un concepto, a pesar de que tenga un conocimiento muy deficiente acerca de sus criterios de aplicación. Finalmente, resulta cuanto menos extraño defender que los criterios compartidos relativos al concepto son los criterios que determinan el valor de verdad de las proposiciones de sistemas jurídicos particulares. Prueba de ello es que dos sujetos de dos sistemas distintos pueden emplear distintos criterios con respecto a las proposiciones de su sistema, aunque pueda afirmarse que comparten los criterios de aplicación del concepto. Y, aunque podamos afirmar que un sujeto ha adquirido el concepto de derecho, es posible y frecuente que no conozca los criterios que determinan el valor de verdad de las proposiciones en su sistema jurídico. Sobre estas últimas cuestiones, vid. HIMmA, 2002: 161 y ss. 
constatación de la controversia dejaría constancia de que el derecho nada prevé sobre la cuestión.

Muchas han sido las estrategias de respuesta que tratan de preservar las tesis positivistas básicas. Por un lado, en ocasiones se ha negado que la cantidad y la entidad de los desacuerdos sean suficientes para refutar las tesis centrales del positivismo. Otras estrategias se han orientado a desacreditar los desacuerdos señalados por DwORKIN en tanto que desacuerdos teóricos acerca de lo que el derecho establece, y a ofrecer explicaciones alternativas. Finalmente, se ha tratado de dar cabida a los desacuerdos teóricos como genuinos desacuerdos sustantivos de forma que resulten compatibles con los postulados positivistas básicos. Analizaré brevemente las diferentes posibilidades.

\subsubsection{Los desacuerdos son marginales}

Para determinar si el problema planteado por DwORKIN constituye un desafío fundamental conviene plantearse, en primer lugar, si el problema de los desacuerdos teóricos es lo suficientemente significativo como para socavar las reconstrucciones positivistas. A estos efectos es importante advertir, por un lado, que prácticamente la totalidad de las acciones que llevamos a cabo diariamente están reguladas de algún modo por normas jurídicas. En este sentido, el número de disputas que tienen lugar en los tribunales es muy pequeño en relación con nuestro vínculo directo o indirecto con normas jurídicas.

Si atendemos exclusivamente a los casos que se discuten en los tribunales, puede constatarse, también sin dificultad, que muchos de ellos giran en torno a cuestiones probatorias o de otra índole, que no pueden caracterizarse plausiblemente como disputas sobre los fundamentos del derecho. Con frecuencia ocurre que las partes simplemente utilizan el sistema judicial por cuestiones de interés, por ejemplo para alargar un pago, perjudicar a un tercero, etcétera ${ }^{27}$.

Sólo en determinados supuestos, especialmente en los litigios que llegan a los altos tribunales, tienen lugar desacuerdos que son, al menos en apariencia, acerca de lo que el derecho establece para la cuestión que es objeto del proceso. No obstante, el número de casos que se plantean y resuelven en dichas instancias superiores es muy pequeño en comparación con el número de casos que llega a los tribunales en general —y que ya es, como se ha señalado, muy pequeño si se toma en cuenta el vínculo cotidiano de nuestra conducta con el derecho- ${ }^{28}$.

Además, no todo caso en que un individuo controvierte lo que el derecho establece resulta problemático para el positivismo. Por un lado, porque los desacuerdos relevantes, que cuestionarían la convergencia que destaca el positivista, son aquellos que se producen entre los funcionarios de justicia. Esto es, aunque otros individuos, por ejemplo los abogados, se sirvan de los criterios compartidos para determinar el

27 Vilajosana, 2007: 49 y ss., y 2010: 173 y ss.

28 Vid. LeITER, 2007: 1228 y ss., y VilajosanA, 2007: 49 y ss., y 2010: 173 y ss. Es importante tener además en cuenta si la relevancia de esos supuestos los convierte en algo central del fenómeno jurídico, tanto por lo que respecta a su importancia general, como a la incidencia del desacuerdo teórico en el propio caso en el marco del cual se desacuerda. 
valor de verdad de las proposiciones jurídicas y puedan controvertirlos, su conducta y actitud no constituye la práctica relevante, por lo que tampoco sus discusiones y argumentos determinarán que esta no existe. Por otro lado, el hecho de que un individuo o un grupo de individuos que sí son funcionarios de justicia ponga en cuestión lo que el derecho establece todavía no atenta contra el carácter convencional del derecho, que requiere de una práctica generalizada de reconocimiento, y no de unanimidad. Una línea de respuesta a la crítica dworkiniana podría enfatizar entonces que, puesto que el positivismo ilumina ampliamente el fenómeno, no habría que abandonarlo por un problema que es residual ${ }^{29}$.

A efectos de mostrar que el número de desacuerdos teóricos que requieren de una explicación plausible en un marco positivista es todavía menor, podría distinguirse entre los desacuerdos teóricos y los que versan sobre cuestiones interpretativas. En este sentido, podría sugerirse que la mayor parte de los desacuerdos que, al menos en apariencia, versan sobre lo que el derecho establece, son desacuerdos respecto de cómo interpretar los textos jurídicos, pero que estos no atentan contra los postulados positivistas básicos, que requieren simplemente un acuerdo en las fuentes del derecho. Así, aunque se defienda que los desacuerdos que recaen sobre la jerarquización de los cánones son abundantes — puesto que los operadores jurídicos cuentan siempre con un conjunto de cánones que conducen a múltiples opciones interpretativas y no es frecuente que se establezca jurídicamente un orden de prelación entre ellos- puede sostenerse al mismo tiempo que estos no atentan contra los postulados positivistas toda vez que lo fundamental es el acuerdo en las fuentes, y no en su contenido. Entonces, si dejamos de lado los desacuerdos interpretativos, el número de desacuerdos teóricos susceptibles de ser explicados se reduce sustancialmente ${ }^{30}$.

En contraste con lo anterior, entiendo, por un lado, que es necesario cierto consenso acerca del contenido de las fuentes para dar sentido a la función que desempeñan tanto las fuentes como los criterios para identificarlas. Defenderé, además, que los desacuerdos acerca de la interpretación, que sí son relevantes a efectos de la problemática de los desacuerdos, no son tan abundantes como en ocasiones se asume.

Así, con respecto a la primera cuestión, desde mi punto de vista las condiciones de existencia de un sistema jurídico no pueden agotarse en la práctica de identificar textos

29 Como señala LeiTER (2007: 1239), cuando comparamos el alcance explicativo de distintas teorías resulta preferible una que suponga una explicación simple, que dé cuenta de más aspectos del fenómeno y que deje intactas las creencias y teorías bien asentadas. En este sentido, que una teoría no explique una parte del fenómeno no nos compromete con el abandono de la misma.

30 Vid. Vilajosana, 2007: 49 y ss., y 2010: 173-175. En este mismo sentido, RatTi (2008) defiende que los desacuerdos acerca de la selección de un canon interpretativo específico son de naturaleza extrajurídica y suponen en última instancia desacuerdos concernientes a la existencia de principios morales o axiológicos objetivos. Según RATTI (2008: 308 y ss.), se trata de la elección de una determinada interpretación con respecto a un conjunto de diferentes e incompatibles, pero por hipótesis igualmente justificadas, soluciones jurídicas. La incidencia de la moral en las controversias interpretativas no da la razón a DWORKIN, de acuerdo con RATTI, puesto que tales desacuerdos no pueden ser reconstruidos como desacuerdos sobre las fuentes; no son desacuerdos relativos, por ejemplo, a si el derecho natural tiene o no valor de fuente jurídica. En realidad, son desacuerdos relativos a las fuentes de segundo orden, es decir, a criterios extrajurídicos de elección entre soluciones jurídicas antitéticas a las que puede recurrirse cuando los elementos jurídicos han fracasado. Entonces, de acuerdo con esta reconstrucción, casi todos los desacuerdos son éticos y no jurídicos y versan sobre lo que el derecho debe ser, y no sobre lo que el derecho es. 
sin una actitud crítico-reflexiva respecto de ciertos modos admisibles de otorgarles un contenido. Imaginemos que un individuo considera que el Código Civil español es parte del derecho español pero entiende que su significado debe serle atribuido a partir de un programa informático que asigna significados al azar. Imaginemos que otro individuo considera que su contenido depende de lo que su hijo de diez años dice que expresa. Finalmente, un tercer individuo entiende que aquello que expresa el Código Civil depende del lenguaje ordinario. ¿Diríamos que hay un acuerdo entre los diferentes individuos acerca de que el Código Civil es parte del derecho si no hay un acuerdo básico sobre lo que expresa el Código? Si cada uno, siguiendo su propio criterio, sostiene una interpretación radicalmente diferente de la de los demás respecto de lo que establece el Código Civil, parece que invocar el Código Civil se torna algo superfluo. Dicho en otros términos, si la actividad interpretativa no es constitutiva de la actividad jurídica, la convergencia en las fuentes podría producir los mismos resultados que su ausencia (un total desacuerdo sobre qué normas son válidas) con lo cual podría ser un hecho completamente irrelevante. Por tanto, parece que la convergencia característica de los modelos positivistas estaría desprovista de sentido si no hubiera ningún acuerdo en relación a cómo interpretar las fuentes del derecho ${ }^{31}$.

Por otro lado, considero que aquellas concepciones que enfatizan la existencia de numerosas opciones interpretativas exageran el carácter controvertido de la interpretación jurídica. Es el caso de la posición de GuASTini. De acuerdo con este autor, la existencia de múltiples instrumentos en los sistemas con los que estamos familiarizados supone que el intérprete tiene discreción para optar entre diferentes normas posibles. Pero esto no implica, dice GUASTINI, que cualquier interpretación sea admisible, sino sólo aquellas que están dentro del marco de posibilidades conforme a los diferentes instrumentos interpretativos. No obstante, la existencia de numerosas interpretaciones posibles, que además son cambiantes con el transcurso del tiempo, deja constancia de que el lenguaje ordinario no desempeña el papel que tradicionalmente se le ha atribuido y de que no existen enunciados interpretativos verdaderos ${ }^{32}$.

Me parece un hecho difícilmente controvertible que en los sistemas jurídicos actuales existen múltiples instrumentos interpretativos, y que las convenciones interpretativas son cambiantes. Sin embargo, esto no obsta a que, desde la perspectiva sincrónica, pueda reconocerse que vinculamos las fuentes jurídicas con determinados supuestos no problemáticos. Es decir, a partir de la constatación del hecho de que en la interpretación jurídica rigen diversos cánones e instrumentos interpretativos, no cabe concluir que los jueces tienen siempre discreción. Así, puede reconocerse que hay múltiples instrumentos jurídicos, que estos dependen de la práctica del conjunto de los intérpretes, y que pueden variar con el tiempo en virtud de los cambios en la práctica de dichos intérpretes y, sin embargo, seguir sosteniendo que, con respecto a cada juez individual y desde la perspectiva sincrónica, hay enunciados interpretativos verdaderos. Enfatizar que siempre hay un marco de interpretaciones posibles, dentro del cual el

31 Esta idea es sugerida por Papayannis (2010). En Rodríguez-Perot (2010: 135 y ss.) se señala que entender que sólo se requiere un acuerdo acerca de las fuentes haría que esta tesis fuera compatible con el iusnaturalismo.

32 Guastini (2003 y 2011). Esta es una tesis característica del realismo genovés. A estos efectos, vid. FERRER-RATTI (2011), y CHIASSONI, 2008. 
juez tiene discreción, no supone más que una distorsión de la realidad jurídica, que exagera el carácter controvertido de algunos casos que vienen dados y son resueltos en atención a los diferentes instrumentos interpretativos ${ }^{33}$. Defender que una disposición expresa una multiplicidad de normas posibles nos hace perder de vista que hay un gran número de supuestos regulados que no suscitan dudas. Y, precisamente no suscitan dudas porque hay una caracterización de la norma expresada por la disposición que no es problemática, sin la cual dejaríamos de reconocer que el derecho es un instrumento capaz de guiar la conducta, en alguna medida al menos. Probablemente la descripción más adecuada de la situación sea que el lenguaje ordinario desempeña un papel fundamental en nuestra comprensión de lo expresado por las disposiciones y, en muchos supuestos, la solución que viene dada por atender al lenguaje ordinario no puede ser controvertida apelando a otros instrumentos, puesto que todos conducen a esa misma solución ${ }^{34}$.

Por tanto, entiendo que es necesario tomar en cuenta los desacuerdos acerca de la interpretación en tanto que estos pueden afectar las tesis básicas del positivismo, pero sin exagerar el número de desacuerdos a que los diferentes instrumentos interpretativos dan lugar.

Hemos visto entonces que los desacuerdos, incluso computando los desacuerdos sobre cuestiones interpretativas, no son abundantes si los ponemos en relación con la incidencia del derecho en nuestras vidas. Entonces, como señalé con anterioridad, el positivismo no se vería amenazado puesto que ilumina en gran medida el fenómeno jurídico. Sin embargo, el problema es que la crítica de DwORKIN atenta contra un aspecto central del modelo positivista, que enfatiza la relevancia de la convergencia como elemento fundamental de los sistemas jurídicos ${ }^{35}$. En este sentido, si la crítica dworkiniana afecta a uno de los aspectos básicos del modelo, la poca cantidad y entidad de los desacuerdos no convierten el problema en algo residual. En consecuencia, resulta necesario buscar explicaciones alternativas y plausibles de los supuestos problemáticos, lo que permitirá defender que el positivismo es una buena teoría del derecho. No obstante, que el número y la relevancia de los desacuerdos aparentemente teóricos sean pequeños no es superfluo puesto que ello facilita, como veremos en el próximo apartado, que encontremos explicaciones alternativas para esos pocos supuestos.

\subsubsection{No son genuinos desacuerdos teóricos}

Dos han sido las estrategias principales para defender que los desacuerdos, en apariencia teóricos y, como tales, problemáticos para un positivista, no son genuinos desacuerdos acerca de lo que el derecho establece. Por un lado, se ha defendido que aquellos que discuten están en un error ${ }^{36}$. Por otro lado, que son hipócritas, al ser

33 Distinguiendo entre la perspectiva individual y la de la comunidad interpretativa, y las perspectivas sincrónica y diacrónica, pero con el fin de defender una concepción realista —a la que denomina «realismo jurídico moderado»—, vid. la interesante posición de FerRer BELtrán en Moreso, Prieto SANCHís y FerRer BELTRÁN, 2010: 152 y ss.

34 Vid. MORESO, 1997: 222.

35 SHAPIRO, 2011: 290.

36 LEITER, 2007: 1226. 
conscientes de que no hay respuesta jurídica correcta para la cuestión planteada, no obstante lo cual intentan enmascarar sus argumentos normativos ${ }^{37}$.

En el ámbito moral se ha defendido la teoría del error con un alcance pretendidamente general ${ }^{38}$. De acuerdo con esta posición, los juicios morales pretenden referirse a propiedades morales, pero, dado que tales propiedades no existen, todos los juicios morales son falsos. Reconstruir determinados supuestos que tienen lugar en el ámbito jurídico como casos de error parece algo más sencillo que defender que todos los juicios morales son falsos. Así, no resulta implausible afirmar que en ocasiones los individuos se equivocan puesto que creen que hay una respuesta jurídica con respecto a una cuestión, pero que en realidad no la hay.

En otros casos, los individuos parecen ser conscientes de que no hay respuesta pero discuten como si la hubiese. En tales supuestos los operadores jurídicos deciden en función de lo que les parece que debe ser el derecho, ya sea porque no están de acuerdo con la regulación y la problematizan, o bien porque no hay regulación sobre la cuestión ${ }^{39}$.

La cuestión que quedaría entonces por responder es por qué se discute como si el desacuerdo fuera genuino, si en realidad no se trata de una disputa acerca de lo que el derecho establece. La respuesta obvia parece ser que aquellos que están en error no lo han advertido y que los que actúan con hipocresía no quieren desvelar la verdadera situación. Específicamente, los jueces tienen interés en ocultar que tienen poder y precisamente por ello simulan estar discutiendo acerca de lo que el derecho es, en lugar de acerca de su reforma. Pero, si esto es así, cabe plantearse por qué el lego no lo ha descubierto todavía. Una posible respuesta sería que, en realidad, las personas no tienen mucho conocimiento del derecho y se intimidan por aquel al que consideran experto, o simplemente le tienen deferencia, por lo que no sería sorprendente que no hubieran descubierto que, en algunos casos en que se discute acerca del derecho, en realidad se están introduciendo cambios. No obstante, también participan del debate y son conscientes de él juristas que no se dedican a la resolución de casos, lo que hace más difícil seguir manteniendo que no hay derecho y que siempre que discuten los individuos están en error o son hipócritas, en lugar de tratar de ofrecer otra explicación ${ }^{40}$. Entonces, si bien parece que muchos supuestos pueden ser reconstruidos como instancias de error, hipocresía, o una combinación de ambos, otros casos requieren de una explicación alternativa ${ }^{41}$.

37 Ibid., 1224, y VilajosANA, 2007: 49 y ss., y 2010: 173-175.

38 Especialmente, MACKIE, 1977.

39 En este sentido, vid. LEITER, 2007: 1240 y ss. Las explicaciones que enfatizan que los individuos son hipócritas no encajan bien con algunos de los ejemplos introducidos por DWORKIN, en que el juez decide en un sentido - porque, según él, es lo que dicta el derecho- pese a que manifiesta que preferiría hacerlo en otro. Sin embargo, SHAPIRO (2007: 42) ha sugerido que tales supuestos pueden ser reconstruidos de manera plausible como casos de hipocresía en que el juez persigue objetivos más amplios, que no se limitan al caso concreto que está resolviendo. Por otro lado, si bien generalmente se ha sostenido que hay algunos supuestos de error y otros de hipocresía, no puede descartarse una explicación que combine ambos elementos. Ello ocurriría cuando, en relación con un mismo caso, unos individuos están en error y otros son hipócritas.

40 SHAPIRO, 2007: 42 y ss.

41 Entender en cambio que el error y la hipocresía explican todos los casos conlleva una imagen de la práctica que muchos participantes rechazarían. No puede ser entonces un buen análisis de ella, al menos en tanto análisis interno, que pretende tomar en cuenta — aunque sin asumirla — la perspectiva del participante. Vid. BAYÓN, 1991: 481 


\subsubsection{El positivismo puede dar cuenta de los desacuerdos teóricos}

Existen ciertas respuestas no problemáticas para el positivismo a la crítica de los desacuerdos en el derecho. Así, en muchos de los casos en que parece existir un desacuerdo teórico, en realidad nos hallamos en la zona de penumbra de la regla, en que el juez tiene discreción para decidir. Ello no supone que la decisión sea arbitraria, sino que el derecho como tal no impone una única solución. Por ejemplo, en el nivel de las fuentes del derecho, podría ocurrir que en un sistema jurídico se considere que lo que establece el parlamento siguiendo determinados procedimientos es derecho, pero, sin embargo, se dude acerca de si estas decisiones pueden comprometer a parlamentos futuros $^{42}$. Lo mismo sucede con respecto a la interpretación de las disposiciones, ámbito en el que suele reconocerse que existe un núcleo de casos claros regulados y otros que suscitan dudas. La elección de una determinada interpretación por parte del juez en los casos problemáticos supone un ejercicio de discreción.

Por otro lado, si el desacuerdo acerca de los criterios de validez jurídica estuviese extendido, probablemente nos encontraríamos ante un sistema patológico y, dependiendo de la gravedad de la situación, podríamos incluso dudar de si se trata de una instancia de sistema jurídico ${ }^{43}$.

No obstante, y aunque no todo se discute y generalmente los desacuerdos pueden ser entendidos como marginales, en ocasiones las disputas son acerca de casos centrales y, en términos dworkinianos, parecen enfrentar concepciones en pugna que destacan aspectos distintos de un mismo fenómeno. Es lo que ocurre cuando se produce una disputa interpretativa sobre casos importantes y existen diversas teorías enfrentadas.

Vimos que DwORKIN concibe el derecho como una práctica argumentativa en que se atribuye un propósito capaz de explicarla y justificarla; las exigencias de la práctica se determinan teniendo en cuenta ese propósito. De esta manera, muchas veces se observa que los juristas desacuerdan respecto de si la interpretación literal del precepto es correcta o si debe prevalecer una interpretación que tome en cuenta la intención del legislador. En supuestos de este tipo, lo que está implícitamente en discusión es qué justifica la coerción estatal en mayor medida. Para algunos, la mejor justificación depende de que se satisfaga la seguridad jurídica. Para otros, la justicia sustantiva tiene prioridad. Más allá de que alguna de estas alternativas, o una combinación de am-

42 En este sentido, Coleman (1982: 156 y ss., y 2001: 74 y ss.) distingue, con respecto a los desacuerdos sobre los criterios de identificación del derecho, entre desacuerdos sobre los criterios y desacuerdos sobre qué satisface los criterios. Según COLEMAN, el problema de los desacuerdos señalado por DwORKIN resultaría residual porque hay una amplia convergencia en lo primero. Cuando se producen, los desacuerdos sobre los propios criterios son relativos a casos de la zona de penumbra de la regla de reconocimiento, en que no hay una solución jurídica preestablecida. Por su parte, Himma (2002: 150-154) entiende que los desacuerdos pueden versar también sobre aspectos centrales si son consistentes con el reconocimiento mutuo del estándar como jurídicamente autoritativo. Las afirmaciones anteriores me parecen, no obstante, problemáticas. Considero que las estrategias de este tipo, que enfatizan la distinción entre los desacuerdos sobre los criterios y sobre qué satisface los criterios, o destacan el hecho de que haya un reconocimiento mutuo del estándar como autoritativo, nos conducen a una caracterización muy abstracta de las convenciones, que las convierte en vacías. Esto es, cualquier desacuerdo puede ser descrito como un acuerdo en un nivel superior de abstracción, pero este será sólo un acuerdo aparente, vacío.

43 Vilajosana, 2007: 49 y ss., y 2010: 173 y ss. 
bas, sea la correcta, lo interesante es que la defensa de cualquier solución refleja un compromiso con la justificación del ejercicio de la coerción estatal. Por esta razón, los desacuerdos son perfectamente inteligibles y, ciertamente, inherentes a la práctica jurídica. En el esquema de DwORKIN, entonces, los desacuerdos no son un problema, sino que precisamente dejan constancia de que su teoría reconstruye adecuadamente la práctica. No obstante, para el positivista suponen una amenaza capaz de socavar de raíz su proyecto teórico.

Como respuesta al desafío que plantean los desacuerdos, se han elaborado principalmente dos estrategias que tratan de fundamentar que los desacuerdos teóricos pueden tener cabida en un modelo positivista. Estas estrategias proponen, o bien la sofisticación del modelo convencionalista, o su abandono. Me referiré brevemente a la primera estrategia y expondré con mayor detenimiento la segunda.

En primer lugar, se ha defendido el llamado «convencionalismo profundo» ${ }^{44}$. El positivismo, que enfatiza la relevancia del elemento convencional, parece enfrentado a un dilema por lo que respecta a su reconstrucción de las reglas sociales y al problema del seguimiento de éstas. Ambos cuernos del dilema conllevan que no pueda ofrecer una respuesta adecuada al problema de los desacuerdos. Si, por un lado, entendemos que una regla convencional se agota en el acuerdo explícito en la comunidad de referencia sobre sus aplicaciones correctas, los desacuerdos teóricos no resultan inteligibles puesto que la falta de acuerdo indica precisamente que no hay respuesta. Esta estrategia resulta además problemática dado que tomar en consideración la práctica de aplicación es compatible con multiplicidad de regularidades distintas, por lo que es difícil determinar qué regla se está siguiendo. Esto es, así entendida la regla no puede proporcionar una pauta de corrección porque cualquier aplicación futura puede hacerse concordar con las aplicaciones pasadas. Entender en cambio que el acuerdo recae meramente en los textos nos lleva a una concepción muy pobre acerca de la convención relevante, y a un regreso al infinito, por la necesidad de interpretar, a su vez, los propios enunciados interpretativos. BAYÓN se decanta en cambio por una posición distinta ${ }^{45}$. Este autor ha sostenido la relevancia del acuerdo en los casos paradigmáticos, que deja constancia de la existencia de criterios públicos que no se limitan a esas aplicaciones. Según BAYÓN, «[e]l reconocimiento de los casos paradigmáticos implica dominar una técnica de uso: pero esto, a su vez, no requiere más que un conocimiento tácito de los criterios de corrección, que por tanto no tienen que resultarle a cada individuo que los usa perfectamente transparentes ${ }^{46}$. Esto explicaría ciertos desacuerdos, puesto que «ni el acuerdo mayoritario garantiza que sea ésa la respuesta correcta, ni la eventual falta de acuerdo implica necesariamente que no haya una respuesta correcta. Porque no es el acuerdo explícito en torno a las aplicaciones correctas lo que las define como correctas, sino el trasfondo de criterios compartidos» ${ }^{47}$. Sin embargo, además de las dificultades que genera el confiar en la existencia de una respuesta convencional

44 MOORE, 1987: 150 y ss.

45 BAYÓN, 2002: 76-81. RODRíGUEZ (2008: 13 y ss.) destaca también la problemática que representa tomar en consideración la práctica o la formulación de la regla y entiende que la posición de BAYÓN constituye una posible salida. Vid. también RODRÍGUEZ-PEROT (2010: 140 y ss.).

46 BAYÓN, 2002: 79.

47 Ibid. Determinar el trasfondo de criterios compartidos requerirá, según BAYÓN, de un razonamiento de naturaleza coherentista, siguiendo una especie de equilibrio reflexivo. 
a pesar del desacuerdo, este tipo de posiciones tiene que comprometerse con que los desacuerdos son acerca de cuál es la convención en cuestión, lo que no parece ser una reconstrucción adecuada de muchos supuestos.

Siguiendo la segunda estrategia, SHAPIRO sostiene una posición en cierto modo similar a la de DwOrKIN. No obstante, defiende que aquello acerca de lo que debe indagarse son hechos sociales, manteniéndose por ello en las filas del positivismo. Así, a diferencia de las posiciones positivistas tradicionales, SHAPIRO rechaza privilegiar las convenciones interpretativas. Como DwORKIN, entiende que, para dar sentido a los desacuerdos teóricos, resulta fundamental tomar en consideración el propósito de la práctica jurídica. Además, ambos coinciden en que la metodología interpretativa más adecuada en un sistema depende de cuál concuerda mejor con sus objetivos. Pero, a diferencia de DWORKIN, SHAPIRO no considera que la atribución de un propósito requiera de un ejercicio de filosofía moral y política, sino que lo relevante, aquello sobre lo que debe indagarse, son hechos sociales. En este sentido, según SHAPIRO, la tarea del intérprete jurídico es detectar los objetivos políticos que pretendían alcanzar los que diseñaron el sistema. Por ello, los propósitos relevantes son los que explican la práctica y no los que la justifican. Y va de suyo que estos propósitos podrían ser moralmente deficientes. Para desvelar esos objetivos el intérprete tiene que analizar la estructura institucional y determinar qué objetivos y valores explican mejor la forma que tiene el sistema. Asimismo, la metodología interpretativa correcta para el sistema será la que armonice mejor con los objetivos de aquellos que lo diseñaron ${ }^{48}$.

De acuerdo con SHAPIRO, su reconstrucción no pretende defender la relevancia de ciertos hechos sociales para preservar a toda costa el positivismo, sino que es precisamente el prestar atención a determinados hechos sociales relativos a los que diseñaron el sistema lo que da sentido a tener autoridades. Así, según SHAPIRO, mediante el derecho pretendemos alcanzar determinados propósitos complejos. Dadas las dificultades, entre otras cosas, para determinar objetivos parciales que contribuyen a la satisfacción del propósito último, las deficiencias motivacionales de algunos sujetos, la incapacidad de otros para desempeñar la labor que se les asigna, etc., sería muy difícil y costoso satisfacer los objetivos en cuestión prescindiendo del derecho. Hay por tanto deficiencias en términos de confianza de los sujetos que dificultarían la consecución de los objetivos, que el derecho pretende compensar. En este sentido, el derecho nos permite alcanzar esos objetivos complejos estableciendo una distribución de roles en virtud de la confianza con respecto a las capacidades y el carácter de los diferentes actores. Por ello, afirma SHAPIRO, la metodología interpretativa adecuada en un determinado sistema depende de las actitudes de confianza y desconfianza de quienes lo diseñaron ${ }^{49}$. Así, por ejemplo, la interpretación literal es más acorde con la desconfianza en determinados sujetos para llevar a cabo su parte correspondiente en la actividad compartida, que una interpretación que conceda mayor libertad al intérprete ${ }^{50}$. No tomar

48 SHAPIRO, 2011: 357 y ss.

49 Esto hace que las interpretaciones sean o no correctas dependiendo del actor que las lleve a cabo (SHAPIRO, 2011: 358). Además, hay que tener en cuenta que la confianza con respecto a determinados actores por parte de los diseñadores del sistema generalmente no es absoluta sino relativa a otros actores, y que no es general sino que depende de ámbitos específicos (SHAPIRO, 2011: 363 y ss.).

50 No obstante, SHAPIRO introduce complejas consideraciones que lo llevan a rechazar la correspondencia entre confianza y metodologías que conceden más discreción, y entre desconfianza y metodologías que 
en consideración la distribución de confianza del sistema atentaría contra la propia lógica de tener autoridades para alcanzar esos objetivos complejos y, probablemente, impediría que fueran alcanzados ${ }^{51}$.

Los desacuerdos son entonces inteligibles en su reconstrucción puesto que los individuos pueden discutir acerca de: $a$ ) cuáles son los propósitos del sistema; $b$ ) cuáles son los objetivos parciales y los respectivos roles de los diferentes actores en aras a alcanzar el objetivo general; c) cuál es la distribución de confianza del sistema; d) qué niveles de confianza son más acordes con las diferentes metodologías interpretativas, y e) qué metodologías interpretativas encajan con los propósitos y distribuciones del sistema ${ }^{52}$. Se trataría de disputas genuinamente teóricas, que no dependen de una mera constatación de hechos, y que responden a los mismos principios que suelen adoptarse en la elaboración de teorías científicas ${ }^{53}$. Esto es así puesto que los sistemas jurídicos cuentan con numerosos actores y diseñadores, lo que hace que las labores de extracción de los objetivos del sistema y de la distribución de confianza sean complejas. Asimismo, la adopción de una posición con respecto al vínculo entre las metodologías interpretativas y las actitudes de confianza y desconfianza también requiere de teorización. De este modo, la reconstrucción de SHAPIRO no sólo hace inteligibles los desacuerdos teóricos, sino que permite explicar por qué estos están tan extendidos.

En algunos casos, y dado que generalmente hay muchos diseñadores implicados, es posible que no haya una única ideología subyacente al sistema, o que ésta tenga tan poca entidad que no determine los debates interpretativos. Además, puede ocurrir que las posiciones de los diseñadores sean inestables con respecto a la distribución de confianza de los diferentes actores. Pero, afirma SHAPIRO, seguramente eliminaremos, tomando en consideración los diferentes pasos anteriores, ciertas posibilidades interpretativas. Y, lo que es más importante a efectos del debate acerca de los desacuerdos, SHAPIRO no parece considerar que la inteligibilidad de estos dependa de la existencia de una respuesta. Según SHAPIRO, lo relevante es que su reconstrucción hace inteli-

conceden menor libertad. Así, entiende que hay que tener en cuenta si los diferentes sujetos son o no hipócritas en sus actuaciones. Además, la decisión con respecto a la metodología interpretativa depende también, según SHAPIRO, del grado de conflicto existente con respecto a la disposición que va a ser interpretada. Sobre estas cuestiones, vid. SHAPIRO, 2011: 373 y ss.

51 SHAPIRO, 2011:336 y ss. En otras palabras, existen muchos modos de satisfacer los objetivos generales del sistema. Si los diseñadores no establecieran objetivos más específicos no se satisfaría la función de coordinación del sistema a fin de alcanzar los objetivos generales. Los diseñadores resuelven estas cuestiones adoptando un determinado esquema institucional, del que se desprenden los objetivos más específicos. Si los intérpretes no atendieran a los objetivos — con diversos niveles de abstracción — que han quedado plasmados en el diseño institucional, dejaría de tener sentido la labor de los diseñadores. Pero estos no sólo establecen esos objetivos, sino además el modo de alcanzarlos. Llevan a cabo una determinada distribución de derechos y responsabilidades en atención a consideraciones de competencia y carácter de los miembros del grupo. Por tanto, resulta fundamental, para dar sentido al hecho de tener autoridades, atender a las decisiones de los diseñadores con respecto a la distribución de roles y a la confianza. Finalmente, también le privaría de sentido adoptar metodologías interpretativas no acordes con la distribución plasmada en el sistema (SHAPIRO, 2011: 336 y ss.). Esta explicación se centra en aquellos sistemas en que los participantes actuales de la práctica jurídica los aceptan porque confían en el juicio de las autoridades, por lo que las distribuciones de confianza implementadas resultan fundamentales. No obstante, podría haber sistemas oportunistas en que la aceptación viene dada por la consideración de que las normas son adecuadas moralmente. En estos sistemas la relevancia de la confianza tal y como es presentada en el texto sería distinta. Vid. SHAPIRO, 2011: 350 y ss.

52 SHAPIRO, 2007: 43 y ss., y 2011: 381 y ss.

53 SHAPIRO, 2011: 367. 
gibles los desacuerdos con carácter general, y explica por qué estos tienen lugar; que exista una respuesta correcta para el caso es una cuestión distinta y contingente ${ }^{54}$.

La reconstrucción de SHAPIRO tiene además la virtud de dar cabida a los desacuerdos teóricos de modo que éstos no supongan concepciones en pugna sobre los elementos básicos del derecho. Es decir, los desacuerdos son inteligibles como disputas teóricas, al mismo tiempo que precisamente consolidan su teoría: que el derecho nos permite alcanzar fines complejos a partir de una determinada distribución de confianza, por lo que resulta fundamental identificarla. Aunque la respuesta al problema de los desacuerdos por parte de SHAPIRO supone asumir numerosas consideraciones relativas a su teoría del derecho como plan, algunos de sus argumentos resultarán, como veremos, de utilidad en la propuesta pluralista que aquí se presentará.

\section{LA DISTINCIÓN DE NIVELES DE DESACUERDOS}

En los dos apartados anteriores he expuesto la crítica de DwORKIN relativa al problema de los desacuerdos y algunas de las respuestas que se han ofrecido por parte de los defensores del positivismo. La estrategia que seguiré a continuación consistirá en defender, por un lado, que existen diversos niveles de desacuerdos, que no han sido claramente distinguidos. Y, por otro lado, que no cabe ofrecer una única respuesta a la crítica dworkiniana, sino diferentes argumentos que tomen en cuenta, precisamente, el nivel de desacuerdo que se esté analizando. Ello me conducirá a concluir que, si bien ninguna de las respuestas a DwORKIN es definitiva, una combinación de ellas sí puede serlo.

A partir de los diversos argumentos aparecidos en el debate, pueden distinguirse diferentes niveles en los cuales pueden producirse desacuerdos. El listado no pretende ser exhaustivo, sino sólo dejar constancia de que en el debate sobre los desacuerdos en el derecho se han ofrecido argumentos y contraargumentos en diferentes niveles, y ello muchas veces ha contribuido a que el problema parezca más grave de lo que en realidad es.

Por un lado, en el nivel metodológico las discusiones se centran en qué tipo de concepto es el concepto de derecho. En este nivel, DworKIN ha defendido su modelo interpretativo y ha atribuido al positivismo el modelo criteriológico ${ }^{55}$. Como hemos visto, los positivistas han rechazado esta caracterización de DwORKIN argumentando, entre otras cuestiones, que su proyecto no se centra en el análisis del término «derecho» o que desentrañar la naturaleza del derecho no requiere identificar criterios compartidos de aplicación del concepto. Con carácter general, puede afirmarse que los positivistas hartianos confían en el poder del análisis conceptual para captar el contenido del concepto de derecho y así esclarecer el fenómeno jurídico ${ }^{56}$.

54 SHAPIRO, 2007: 49, y 2011: 383. Es importante atender a ciertas cuestiones consideradas brevemente por SHAPIRO. Por un lado, puede ser difícil determinar quiénes son los diseñadores, o puede que el sistema no los tenga, y esta es una cuestión que puede variar con el tiempo (SHAPIRO, 2007: 55 n. 61 y 62). Además, puede no ser relevante deferir a los diseñadores si estos no son confiables. El aspecto fundamental es que si los diseñadores son confiables (algo que está presupuesto en todo sistema), deferir a sus juicios sobre cómo lograr los objetivos del sistema es la estrategia para alcanzarlos (SHAPIRO, 2007: 46).

55 Vid. DwORKIN, 1986: 45 y ss.

56 HART, 1994: 248 y ss. Vid. también el prefacio a la edición inglesa y el capítulo 1. 
En segundo lugar, puede distinguirse el nivel relativo a los elementos centrales del derecho. En este nivel, las disputas giran en torno a qué es el derecho con carácter general. De esta manera, si se adopta una metodología interpretativa, podrían, por ejemplo, discutirse las ventajas e inconvenientes de defender el convencionalismo o el derecho como integridad. $\mathrm{O}$, en el marco de las concepciones no-interpretativas, puede defenderse la relevancia de determinados hechos sociales pero discutirse cuáles son esos hechos. La posición que se adopte en este nivel no viene determinada por la que se ha adoptado en el nivel metodológico. En este sentido, podrían sostenerse tesis similares en relación a los elementos básicos del derecho, a pesar de que se suscriban metodologías diversas.

En tercer lugar, nos encontramos con el nivel de la interpretación en abstracto. En este nivel, puede defenderse una determinada posición interpretativa con carácter general — por ejemplo, podría enfatizarse la relevancia de las intenciones del legislador- o con respecto a determinados grupos de casos — por ejemplo, en relación a cómo atribuimos significado a los términos morales que aparecen en el derecho- . La teorización y el debate en este nivel generalmente se plasmarán en una discusión acerca de los diversos instrumentos interpretativos, su contenido y su orden de prelación en abstracto. Podría existir acuerdo con respecto a la posición que se adopte en este nivel, a pesar de que se desacuerde en relación a los niveles anteriores. Por otro lado, frecuentemente los autores derivan su posición en el nivel de la interpretación en abstracto de su concepción acerca de los elementos básicos del derecho. Por ejemplo, un partidario del derecho como autoridad puede promover un modelo que tome en consideración las intenciones del legislador ${ }^{57}$.

¿Es problemático para el positivismo que existan disputas en los niveles anteriores? DWORKIN parece asumir que sí. Recuérdese que concibe el derecho como una práctica argumentativa, en la que los individuos discuten acerca del derecho. Los juristas desacuerdan sobre qué establece el derecho en un sistema particular. Pero también los teóricos manifiestan una actitud interpretativa con respecto al derecho, aunque en un nivel de abstracción distinto. Esto es así puesto que, de acuerdo con DwORKIN, o bien entendemos que los teóricos suscriben teorías semánticas, lo que conlleva no poder reconstruir adecuadamente los desacuerdos, o bien se los concibe como proponiendo teorías normativas en conflicto en el marco de una concepción interpretativa del derecho. De este modo, DwORKIN intenta mostrar que el debate que mantiene con HART y otros teóricos deja constancia del carácter argumentativo del derecho y de que todas las teorías, incluida la integridad, compiten entre sí en el plano normativo. Así, DWORKIN cree que subyace a la posición convencionalista de HART una preocupación fundamental por la legalidad ${ }^{58}$.

La cuestión central es si la propia existencia de disputas entre los teóricos, que se manifiesta en los desacuerdos en los tres niveles anteriores, deja constancia del carácter argumentativo del derecho y si el hecho de que DwORKIN pueda dar sentido al resto de posiciones en el marco de su concepción interpretativa constituye un argumento

57 En este sentido, MARMOR: 2005, capítulo 8. RAZ (1996), en cambio, niega tal conexión.

58 Así, DwORKin (2006: 183 y 188) reconstruye la respuesta de HART en el Postcript, que defendía la naturaleza convencional del derecho y la neutralidad valorativa de su proyecto positivista, como una concepción sustantiva de la legalidad. 
a favor de su posición. Como trataré de mostrar, considero que, aunque es un hecho incontestable que los teóricos discuten sobre cuál es la metodología correcta para estudiar el derecho, cuáles son los elementos centrales de la práctica jurídica y qué metodología interpretativa es la más adecuada en abstracto, no puede contar como un argumento a favor de la teoría de DwORKIN que su reconstrucción pueda dar sentido a las disputas entre los propios teóricos.

Pensemos en la práctica que consiste en la obtención de conocimiento. En dicha práctica encontramos sujetos que, siguiendo el método científico, investigan y elaboran teorías acerca de los fenómenos del mundo. Por otro lado, imaginemos que un grupo de chamanes afirma que el conocimiento se obtiene a partir de la lectura de la borra del café. Mediante esta lectura, los chamanes piensan que están invocando a los dioses, que se manifiestan dando diferentes formas a la borra, permitiéndoles así adquirir conocimiento sobre distintos aspectos del mundo. Los chamanes creen que la práctica de adquirir conocimiento consiste precisamente en la invocación de los dioses, y consideran que los científicos han desarrollado un mecanismo distinto para invocarlos. Podrían discutir entonces con ellos acerca de cuál es el mejor modo de invocar a los dioses. En cambio, de acuerdo con los estándares científicos, la discusión con los chamanes carece de sentido. Si evaluamos ambas concepciones, el hecho de que una de ellas sea capaz de explicar por qué las controversias entre científicos y chamanes tienen sentido, y la otra no, resulta inconcluyente. Este ejemplo pretende mostrar por qué el hecho de dar sentido a los desacuerdos entre los teóricos no puede contar como argumento a favor de una determinada teoría. Volviendo concretamente al debate entre positivistas y dworkinianos, así como no cuenta a favor del chamán la posibilidad de interpretar que los científicos están involucrados en su misma práctica de obtención de conocimiento, tampoco favorece a DWORKIN el hecho de que en su reconstrucción el positivismo asuma una actitud interpretativa. En realidad, que los teóricos del derecho desacuerden no resulta en absoluto sorprendente. Esta es una característica invariable de la reflexión filosófica. Lo que realmente afecta al positivismo hartiano son los desacuerdos entre los propios participantes, léase los funcionarios públicos, respecto de la identificación del derecho válido en la comunidad.

En los tres primeros niveles que acabo de exponer, los desacuerdos versan sobre el derecho con carácter general. Los cuatro siguientes niveles que mencionaré se refieren a desacuerdos que tienen lugar en sistemas jurídicos específicos. Pueden distinguirse, cuanto menos, el nivel de la identificación del derecho, el nivel de las fuentes, el nivel de la interpretación en un sistema específico y el nivel de la solución jurídica para un determinado supuesto.

En el nivel de la identificación del derecho se discute cuáles son los criterios de validez compartidos que conforman la regla de reconocimiento en un sistema jurídico específico.

Podría desacordarse, además, sobre cuáles son las fuentes jurídicas de un sistema jurídico específico, así como el orden de prelación entre ellas. Aquí conviene distinguir dos niveles diferentes, el de las fuentes-proceso, y el de las fuentes-producto.

En relación a las fuentes-proceso del sistema, puede discutirse si la costumbre, los precedentes, la argumentación moral o ciertos pactos históricos celebrados antes 
de la primera constitución, por ejemplo, son fuente del derecho con carácter general. Podría pensarse que estos desacuerdos no son algo distinto de los desacuerdos sobre la propia regla de reconocimiento, pero esto no es así. En este sentido, puede haber acuerdo sobre las fuentes-proceso, pero desacuerdo en la regla de reconocimiento. Un grupo de jueces podría entender que las costumbres son fuente del derecho porque así lo dispone la constitución. A su vez, otro grupo podría entender que es derecho lo que establecen los documentos normativos y la costumbre. Evidentemente, si la constitución fuese modificada y ya no mencionase la costumbre, el primer grupo dejaría de considerarla una fuente, mientras que para el segundo este hecho no alteraría el estatus de la costumbre como proceso productor de normas jurídicas.

En cuanto a las fuentes-producto del sistema, hay que tomar en consideración que, aun acordando sobre la regla de reconocimiento y sobre las fuentes-proceso, los funcionarios podrían desacordar sobre si una determinada costumbre es parte del derecho mercantil, por ejemplo. Supongamos que nadie duda que la costumbre en general es una fuente-proceso, pero se discute si se han verificado las condiciones fácticas necesarias para la creación de una costumbre en concreto, como aquella que establece que en ausencia de estipulación en contrario los costes de entrega corren a cargo del vendedor. En cualquier caso, este parece ser un puro desacuerdo fáctico, que no afecta a los criterios de validez jurídica.

La controversia puede centrarse también en el significado de las fuentes de un sistema jurídico especifico. Por un lado, podrían cuestionarse los criterios interpretativos, es decir, aun existiendo acuerdo sobre todo lo anterior, todavía podría discutirse qué cánones interpretativos son válidos y, en todo caso, su prelación. Ya hemos visto que cierto acuerdo en este nivel es determinante. Además, la discusión podría recaer sobre el significado de las fuentes-producto, es decir, incluso acordando sobre todo lo demás, podría desacordarse sobre el significado de una concreta disposición normativa. Sin embargo, si prestamos atención a este tipo de desacuerdos, resulta claro que estos no pueden ser teóricos. Por ejemplo, si en el nivel anterior se acuerda en que el canon aplicable es la intención del legislador, pero se desacuerda sobre el contenido de la disposición, o bien en realidad no hay un genuino acuerdo en el nivel previo, esto es, estamos frente a un desacuerdo interpretativo, sobre cuál es el canon válido (¿ise trata de la intención del legislador al momento de dictarse la norma, al momento de decidirse el caso, de un legislador ideal, etc.?), o bien el desacuerdo es fáctico (sobre cuál era la intención del legislador). Habiendo acuerdo sobre estas cuestiones, parece entonces que carece de sentido plantear que pueda existir acuerdo en el canon y desacuerdo en el significado de la disposición.

Otro nivel distinto se relaciona con la respuesta que prevé un sistema determinado para un supuesto específico. Es importante distinguir este nivel, puesto que podría darse un acuerdo en el nivel del significado pero desacordarse sobre cómo resolver un supuesto (por ejemplo, porque se reconoce que hay multiplicidad de instrumentos que pueden ser considerados, pero se discute acerca del mejor modo de resolver un supuesto), y podría existir acuerdo en la solución de un caso, pese a haber desacuerdo en los cánones específicos — de hecho, como vimos, generalmente los cánones coinciden en la solución de un gran número de supuestos-. 
Asimismo, es frecuente que se produzcan desacuerdos acerca de qué tipo de desacuerdo se está manteniendo (metadesacuerdos). Por ejemplo, si bien generalmente se ha defendido que la disputa acerca de qué tratamiento teórico deben tener los términos morales está en el segundo nivel (¿ison incorporados al derecho o son estándares extrajurídicos?), este modo de clasificar la disputa ha sido controvertida, entendiendo que en realidad se trata de un debate interpretativo sobre el contenido de los términos morales en un sistema específico (¿refieren a la moral crítica, a la moral positiva, a lo que los legisladores consideraban moralmente correcto?) ${ }^{59}$. Además, en ocasiones se discute sobre el carácter de la disputa, resultando controvertido si ésta se ubica en el plano jurídico o moral ${ }^{60}$. Finalmente puede discutirse la relación entre los diversos niveles. Por ejemplo, hemos visto que la crítica inicial de Dworkin, que enfatiza el vínculo entre el significado de la palabra «derecho» y el acuerdo en los criterios de validez jurídica en un sistema jurídico determinado, conecta los niveles primero y cuarto, cuestión que ha sido controvertida por los positivistas.

\section{UNA RESPUESTA PLURALISTA}

Fruto de su análisis, el positivista destaca que el aspecto central del derecho es la convergencia de determinados individuos en ciertas cuestiones. Entonces, si tras un análisis cuidadoso de lo que hacen y dicen los participantes, y de lo que presuponen en sus actuaciones, concluyéramos que los individuos desacuerdan con frecuencia y que sus disputas tienen un carácter teórico puesto que no pueden ser explicadas plausiblemente de otros modos, la teoría positivista se vería seriamente amenazada. Por su parte, Dworkin destaca que la práctica jurídica es interpretativa. No obstante, sostiene que el carácter interpretativo no es transparente a los participantes, sino que podemos afirmar que existe cuando nuestro comportamiento colectivo al usar el concepto de derecho se explica mejor si consideramos que su uso correcto depende de la mejor justificación de la práctica en que aparece. Esto no requiere de una mera constatación empírica, sino que depende de si da sentido a cómo los participantes discuten y a lo que hacen cuando presentan argumentos ${ }^{61}$. Si el desacuerdo no ocupara un lugar central en la práctica, o si no tuviera los rasgos que DwORKIN le atribuye, su defensa del concepto interpretativo de derecho y, en consecuencia, del derecho como integridad, no sería adecuada ${ }^{62}$.

Aunque en la discusión sobre la incidencia de los desacuerdos se han empleado ejemplos que pertenecen a los diferentes niveles, es fundamental tener en cuenta si existen entre los participantes disputas frecuentes en el nivel de la solución jurídica, que vengan dadas por desacuerdos en el nivel de los criterios de identificación o en el de los criterios interpretativos, y que pongan de manifiesto la existencia de un des-

59 FERRER BeLtrán, 2010: 167 y ss.

60 En este sentido, vimos que RATTI afirma que los ejemplos de DwORKIN son en realidad casos de disputas extrajurídicas. En esta misma línea, COLEMAN ha defendido que los desacuerdos resultan inteligibles en un marco positivista aunque sean reconstruidos como desacuerdos morales.

${ }^{61}$ DwORKIN, 2011: 158 y ss.

62 Esto es así en tanto que el concepto sea interpretativo, es condición necesaria para sostener la concepción del derecho como integridad. 
acuerdo teórico que pueda ser entendido, en última instancia, como un cuestionamiento de que la convergencia constituye uno de los elementos centrales del derecho.

Por lo expuesto con anterioridad, puede ya anticiparse parcialmente la respuesta a DwORKIN. En primer lugar, los desacuerdos en apariencia teóricos son un fenómeno menor si tenemos en cuenta la incidencia del derecho en nuestras vidas, lo que facilita hallar explicaciones alternativas para los casos en que dichos desacuerdos se producen.

En segundo lugar, todo sistema jurídico cuenta con una serie de normas que regulan aspectos básicos del funcionamiento de sus instituciones jurídicas, con respecto a las cuales existe una amplia convergencia y no puede advertirse que se haya desarrollado una actitud interpretativa. Es el caso, por ejemplo, de las reglas que establecen qué decisiones judiciales son definitivas y los procedimientos para hacerlas cumplir. Este tipo de normas otorga a los ordenamientos jurídicos la estabilidad necesaria para su existencia. Si bien la presencia de piezas intocables no nos ayuda a hacer inteligibles los desacuerdos acerca de lo que el derecho establece, deja constancia de que en el derecho existe un importante núcleo de acuerdo acerca de estas cuestiones fundamentales, lo que fortalece las tesis positivistas ${ }^{63}$.

En tercer lugar, es poco habitual que el desacuerdo verse sobre los criterios de identificación del derecho. Pero, cuando es así, generalmente puede ser explicado de modo plausible como un caso de desacuerdo marginal en que el juez tiene discreción, compatible con la idea de convergencia exigida por el positivismo. Y, si en una determinada comunidad, los desacuerdos sobre los criterios estuvieran ampliamente extendidos, creo que dudaríamos seriamente que esa comunidad tenga derecho. Más bien, creeríamos estar frente a una institución o práctica social patológica, incapaz de satisfacer la mayoría de las funciones que consideramos típicamente jurídicas ${ }^{64}$. Los desacuerdos acerca de las fuentes serían reconducibles, o bien a desacuerdos empíricos, o a desacuerdos sobre los criterios de identificación.

En cuarto lugar, y por lo que respecta a los desacuerdos interpretativos, considero que no basta para escapar al problema de los desacuerdos con señalar que existe convergencia en las fuentes. Ello, en tanto cierta convergencia con respecto a los modos de interpretarlas es necesaria para que el derecho cumpla con su función de guía de conducta y tenga sentido la propia idea de una regla de reconocimiento — que no se limita

63 Vid. MORESO (2010a), quien ha sugerido que, para que exista un sistema jurídico, la controversia no resulta problemática siempre que algunas reglas procedimentales relativas a quiénes son las autoridades finales y a cuándo sus decisiones son obligatorias estén excluidas de la discusión. Sin embargo, y pese a que hay normas que gozan de gran estabilidad, no parece haber razones para afirmar que éstas no pueden ser controvertidas en ocasiones y variar con el tiempo. En este sentido, FERRER BELTRÁN (2010: 179). Es cierto que son normas menos cambiantes y que las disputas con respecto a ellas son sobre supuestos marginales. También lo es que cuestionarlas todas al mismo tiempo podría atentar contra la estabilidad necesaria para que el derecho pueda guiar la conducta. No obstante, nada impide que algún aspecto de ellas pueda controvertirse en un momento dado. Además, es evidente que diacrónicamente todo puede variar. En cualquier caso, me parece que la cuestión de interés a efectos de los desacuerdos continúa vigente más allá del debate acerca de las piezas intocables. El núcleo de la discusión que aquí nos ocupa gira alrededor de si, sincrónicamente, cuando se discuten diferentes aspectos acerca de lo que el derecho establece, se está discutiendo sobre algo preestablecido o no; y, si nos resulta intuitivo reconocer que la disputa es acerca del derecho, cómo esto afecta a las tesis positivistas básicas. Parecería entonces que, haya o no piezas intocables, el problema de los desacuerdos teóricos y su reconstrucción en el marco positivista persiste.

${ }^{64}$ En este sentido, ViLAJOSANA, 2007: 49 y ss., y 2010: 173-175. 
a identificar textos a los cuales el intérprete puede dotar de cualquier contenido-. Por tanto, desde mi punto de vista, es necesario un amplio acuerdo sobre los instrumentos interpretativos. Del mismo modo que ocurre con el nivel de la identificación, creo que existe un acuerdo extendido en este nivel, que los desacuerdos son marginales, y que si las controversias fueran extendidas dudaríamos acerca de si nos hallamos ante un sistema jurídico. En todo caso, reconocer la existencia de instrumentos interpretativos no supone admitir que todo es controvertido, como se desprendería de una posición realista extrema, sino que la propia práctica jurídica evidencia un acuerdo extendido sobre cómo están regulados numerosos supuestos.

En este ámbito, como señalé, existe un importante núcleo de supuestos no controvertidos, pero también puede observarse que habitualmente los sujetos invocan distintos criterios interpretativos para fundamentar diferentes soluciones para un mismo caso. ¿Se trata de genuinos desacuerdos teóricos que ponen en cuestión las tesis positivistas? La cuestión central a considerar es si lo que da más sentido a los desacuerdos en este nivel es una reconstrucción à la DWORKIN, en la cual los participantes intentan ofrecer la mejor justificación de la práctica jurídica. Atender a los argumentos que los juristas presentan, y al modo en que discuten, no parece dar la razón a DWORKIN. Por un lado, los abogados suelen ofrecer diversos argumentos para defender su posición, y su criterio de selección tiene que ver con lo que maximiza sus probabilidades de ganar el pleito. De hecho, van acumulando argumentos de distinta índole, que difícilmente pueden ser presentados como la expresión de una postura iusfilosófica coherente. Por su parte, no parece que los jueces tengan una práctica esencialmente distinta. También ellos en los casos difíciles, como ha mostrado LEITER con respecto al ámbito anglosajón, seleccionan sus argumentos de modo oportunista. De ello deja constancia el hecho de que muchas veces adhieren - y parecen hacerlo como una cuestión de principios- a un canon interpretativo que, sin embargo, dejan de lado en otras decisiones, sin resaltar ninguna particularidad del caso que lo justifique ${ }^{65}$. Un análisis de los repertorios jurisprudenciales muestra que los jueces, lejos de mantener una disputa teórica, presentan una fachada de justificación para fundar sus decisiones. En esta línea, me parece más adecuado defender que en los casos problemáticos contamos con convenciones eminentemente jurídicas, que posibilitan la defensa de diversas posiciones. Y, si bien en estos supuestos los sujetos presentan sus opiniones afirmando que el derecho exige esa solución jurídica, la teoría del error y/o la hipocresía parecen el mejor modo de dar cuenta de lo que realmente ocurre.

Además, hay un tercer grupo de supuestos, en que los individuos no están en error ni son hipócritas, que tampoco suponen un desacuerdo teórico susceptible de socavar al positivismo. Es el caso en que la mejor interpretación de lo que los propios sujetos dicen y hacen nos lleva a concluir que, aunque asumen que no hay derecho, entienden que es parte de su función adoptar una decisión para el supuesto, por lo que intentan identificar la respuesta que mejor encaja con el sistema, la que les parece moralmente más defendible, la que consideran que tendrá mejores consecuencias, etcétera.

Existe un último grupo de casos que podría resultar problemático. En ocasiones, se discute acerca del significado de un término de modo que los diversos intervinientes

${ }^{65}$ LEITER, 2007: 1232 y ss. 
en la disputa presentan concepciones en pugna acerca de los rasgos centrales del objeto al que el término refiere. Entonces, si entendemos que, conforme al modelo positivista, el valor de verdad de las proposiciones depende de existencia de convergencia entre los participantes también con respecto a la interpretación de las disposiciones, tales desacuerdos carecerían de sentido puesto que el propio debate manifestaría la ausencia de un significado preestablecido. Sin embargo, creo que el positivismo puede ofrecer una respuesta satisfactoria también para estos casos si recurrimos a las aportaciones que, en el ámbito de la filosofía del lenguaje, han realizado los nuevos teóricos de la referencia.

Del mismo modo que ocurre en nuestras prácticas lingüísticas cotidianas, determinados términos que aparecen en los textos jurídicos manifiestan ciertos rasgos destacados por los partidarios de las nuevas teorías de la referencia ${ }^{66}$. Así, en ocasiones empleamos determinados términos para referir pese a contar con información deficiente con respecto a los objetos. Empleamos dichos términos para referir a una clase, que asumimos que tienen una naturaleza profunda. Y somos capaces de referir puesto que formamos parte de una cadena de comunicación, que nos remonta en última instancia a ejemplares de la clase, aunque nuestras creencias respecto a los objetos que pertenecen a la clase sean muy pobres y falibles. Entonces, para que haya una discusión con sentido los sujetos deben formar parte de la misma cadena de comunicación, que les remonte a instancias de la misma clase. Pero además, para que se produzca un desacuerdo sustantivo, debemos ser competentes en el uso del término, lo que exige que seamos capaces de emplearlo normalmente y que contemos con un estereotipo acerca de la clase. Por otro lado, el uso correcto del término dependerá de cuál es la naturaleza de la clase a la que referimos. La identificación de qué rasgos son determinantes puede estar en manos del hablante común o de expertos. Y, puesto que su determinación requiere de teorización, los desacuerdos pueden ser explicados como argumentos en conflicto que tratan de capturar los rasgos fundamentales de la clase, que determinan la pertenencia a la misma ${ }^{67}$. Entonces, si entendemos que el derecho pretende guiar la conducta y, precisamente por ello, se expresa mediante el lenguaje ordinario, y el lenguaje ordinario frecuentemente responde a la reconstrucción ofrecida por los nuevos teóricos de la referencia, resulta plausible entender que el lenguaje del derecho se ajusta también, cuando incorpora tales términos, a dicha reconstrucción. Y, dado que la consideración de las nuevas teorías de la referencia depende de cómo se usan los términos, tomarlas en cuenta respeta la convergencia que se halla en la base del esquema positivista, precisamente porque depende de que tal convergencia exista. En otras palabras, asumir una concepción no convencionalista como la aquí propuesta depende de la propia conducta y actitudes de los participantes, por lo que el carácter convencional del derecho no tiene por qué implicar una concepción convencional de nuestras prácticas lingüísticas.

En supuestos como los anteriores, parece que los sujetos discuten acerca del concreto significado de una disposición, más allá de que acuerden sobre los cánones vi-

66 Vid. KRIPKe, 1980, y Putnam, 1975.

67 Esto es así incluso si acabamos descubriendo que no hay un único rasgo esencial. El modelo hace inteligible por qué los sujetos desacuerdan, aunque en determinados casos no haya una única respuesta a la cuestión. 
gentes en la comunidad. En este sentido, contra lo que venía sosteniendo, parece que podrían existir desacuerdos en el nivel del significado de las fuentes-producto pese a acordarse en los niveles previos, porque podría aceptarse que el lenguaje ordinario es el canon interpretativo para ese caso, pero discutirse, por ejemplo, si los hongos son o no plantas, o si los tomates son o no frutos, y qué papel pueden desempeñar los expertos en la determinación de la respuesta.

Por otro lado, tomar en consideración las nuevas teorías de la referencia no sólo hace inteligibles los desacuerdos acerca de la naturaleza de la clase, sino también otros grupos de desacuerdos.

En ocasiones, se cuestionará si un determinado término responde a la reconstrucción de los nuevos teóricos de la referencia o al esquema convencionalista. Esto es posible, por un lado, porque el propio carácter convencional de un término no tiene que resultar transparente a aquellos que lo emplean ${ }^{68}$. Además, la determinación de que los sujetos están empleando un término conforme a las nuevas teorías de la referencia no supone una mera constatación empírica, sino que requiere de cierta teorización sobre nuestras asunciones en el uso de los términos, lo que se pone de manifiesto en nuestras reacciones ante situaciones contrafácticas.

A veces ocurre, con respecto a algunos términos, que existen dos cadenas de comunicación distintas, una que remonta al uso cotidiano del término y otra al uso experto, y la disputa puede recaer precisamente en cuál es la cadena de comunicación en la que se inserta el término que aparece en las disposiciones jurídicas. La determinación de la cadena de comunicación adecuada también exige de teorización, por lo que podrán tener cabida desacuerdos con sentido acerca de estas cuestiones. Sería el caso, por ejemplo, en que la normativa introduce un impuesto relativo a los frutos, y se discute - puesto que es evidente que existen diferencias en este ámbito entre el uso ordinario y el uso experto- si los tomates se hallan o no comprendidos en la regulación ${ }^{69}$.

En otro grupo de supuestos, la deferencia a determinados expertos no es controvertida. Entonces, si entendemos que el término se ajusta al modelo de las nuevas teorías de la referencia, el desacuerdo entre los propios expertos generalmente no planteará problemas dado que podrá ser reconstruido como intentos en conflicto de identificar los rasgos centrales de la clase. Así, por ejemplo, desde el punto de vista de las nuevas teorías de la referencia, podría defenderse que el debate de la dogmática penal respecto a la causalidad no es una disputa verbal ni tampoco ideológica; se trata, más bien, de una discusión que pretende desentrañar cuál es su naturaleza.

Otras veces existe un uso extrajurídico del término y se discute si se ha dado lugar a una nueva cadena de comunicación, esto es, si se ha producido una nueva fijación de la referencia estrictamente jurídica. Esto exigirá un análisis que no se limita a la

\footnotetext{
68 BuRGE, 1975: 250.

69 Estoy empleando un ejemplo similar al del caso Nix vs. Hedden, resuelto por la Corte Suprema norteamericana en 1893 (149 US 304, 1893), aunque he introducido modificaciones en el mismo — hago referencia a frutos, y no a verduras - a efectos de dejar de lado ciertas complejidades del caso original. MORESO (2010b: 41 y ss.) considera en cambio que la solución del supuesto requiere que atendamos a consideraciones pragmáticas, y no estrictamente semánticas.
} 
constatación de determinados hechos, lo que explicará que pueda haber desacuerdos sustantivos también en este punto ${ }^{70}$. Imaginemos que la normativa castiga el tráfico de plantas alucinógenas, y que se suscita el problema de si el tráfico con hongos alucinógenos está o no incluido. El hecho de que se planteen dudas con respecto a si el caso de los hongos está o no regulado deja constancia de que es controvertido si el lenguaje jurídico se sirve del lenguaje ordinario - que, en este caso, remite al uso experto- o si cabe entender que se ha producido una nueva fijación de la referencia. Si esto último ocurriera, habría una nueva cadena de comunicación estrictamente jurídica que, por ejemplo, supondría que el supuesto de los hongos sí estuviera incluido en la normativa por entender que el significado del término está ligado a la intención del legislador ${ }^{71}$.

Además, frecuentemente estará en cuestión quiénes son los sujetos que deben identificar los rasgos centrales de la clase. Creo que las consideraciones apuntadas por SHAPIRO con respecto a la distribución de confianza, que se plasma en el propio diseño institucional del sistema, tienen incidencia para determinar quiénes son los sujetos relevantes. Por ejemplo, pensemos en la disposición penal que emplea el término «causalidad» y en cuál es la distribución de confianza que se plasma en el sistema con respecto al mismo. En este ámbito las diferentes conductas tienden a estar reguladas de manera taxativa y suele considerarse al juez como un mero aplicador de las disposiciones, que no realiza valoraciones. Sin embargo, en el caso de la causalidad el legislador ha omitido establecer requisitos para la aplicación del término, aun habiendo tenido la oportunidad de hacerlo. Los jueces, por su parte, recurren en sus sentencias a las reconstrucciones de la dogmática. Estos han ido teniendo en cuenta diversas teorías dogmáticas, asumiendo que éstas dan cuenta, cada vez mejor, de supuestos problemáticos y que suponen progresivos intentos de desentrañar su naturaleza. El legislador, al modificar otras partes de la regulación penal, no ha introducido nuevas consideraciones con respecto a la causalidad, esto es, no se ha comprometido con una teoría específica acerca de la misma. Teniendo en cuenta lo anterior, podría concluirse que el sistema manifiesta una actitud de confianza con respecto a la dogmática jurídico-penal en relación con significado de determinados términos, lo que se plasma en la falta de especificación en la regulación y en las diferentes atribuciones y limitaciones previstas por la normativa. Establecer quiénes son los sujetos relevantes a efectos de desentrañar la naturaleza del fenómeno requerirá de teorización, lo que no impide que, en última instancia, la indagación apunte a hechos sociales.

Finalmente, existe un grupo de supuestos controvertidos en que se invocan diferentes instrumentos interpretativos y el lenguaje ordinario entra en la argumentación como un elemento más. En tales supuestos no hay una única respuesta jurídica para la cuestión y entran en juego consideraciones normativas para determinar la solución del caso.

$70 \mathrm{Y}$, generalmente, las propias dudas acerca de si ha surgido una nueva cadena dejarán constancia de que ésta no se ha consolidado y de que, probablemente, como ocurrió en algún momento con respecto al término «Madagascar», la referencia está indeterminada. El ejemplo de Madagascar fue introducido inicialmente por EVANS (1973).

${ }_{71}$ Este caso fue discutido por la jurisprudencia alemana y concluyó con sentencia del BGH ( 25 de octubre de 2006), que establece que los hongos se hallan incluidos en la normativa que hace referencia a las plantas. Analizando este supuesto, MONTIEL y RAmírez, 2010. MoreSo (2010b: 31 y ss.) expone y discute tanto este supuesto como el caso de la jurisprudencia norteamericana relativo a los tomates. 
Los desacuerdos anteriores son posibles en el marco de una concepción positivista acerca del derecho puesto que el modo en que se usan los términos en la práctica es determinante. En este sentido, no problematizan el acuerdo básico que requiere el positivista, ni subyace a ellos una concepción sobre los elementos básicos del derecho. Así, estos desacuerdos, que son profundos, no presentan visiones enfrentadas sobre los fundamentos del derecho, sino que se limitan a disputas relativas a la naturaleza de un determinado objeto al que refieren las disposiciones jurídicas. En otras palabras, si los desacuerdos teóricos requieren de concepciones en pugna acerca del derecho, el positivismo no puede darles cabida. Pero tampoco necesita hacerlo puesto que puede recurrir a explicaciones alternativas que permiten reconstruir tales desacuerdos con un alto grado de plausibilidad.

\section{BIBLIOGRAFÍA}

BAYÓN, J., 1991: La normatividad del derecho: deberes jurídicos y razones para la acción, Madrid: Centro de Estudios Constitucionales.

- 2002: «Derecho, convencionalismo y controversia», en E. NAVARRO y C. REDONDO (comps.), La relevancia del derecho, Barcelona: Gedisa, 57-92.

Burge, T., 1975: «On knowledge and convention», Philosophical Review, 84: 249-255.

Chiassoni, P., 2008: «On the wrong track: Andrei Marmor on Legal Positivism, Interpretation and easy cases», Ratio Juris, vol. 21 (2): 248-267.

Coleman, J., 1982: «Negative and positive positivism», Journal of Legal Studies, 11: 139-164.

- 2001: The Practice of Principle: In Defence of a Pragmatism Approach to Legal Theory, Oxford: Oxford University Press.

Coleman, J., y Simchen, O., 2003: «Law», Legal theory, 9: 1-41.

DONNELlAN, K., 1970: «Proper names and identifying descriptions», Synthese, 21: 335-358.

DwORKIN, R., 1977: Taking rights seriously. Citado por la traducción de GuASTAVINO, M., 1984: Los derechos en serio, Barcelona: Ariel Derecho.

- 1986: Law's Empire, Oxford: Hart Publishing.

- 2006: Justice in Robes, Cambridge, Harvard University Press. Citado por la traducción castellana de M. IgLeSiAS y I. ORTIZ DE URBINA, 2007: La justicia con toga, Barcelona: Marcial Pons.

- 2011: Justice for Hedgehogs, Cambridge: Harvard University Press.

EndicotT, T., 2001: «Herbert Hart and the semantic sting», en J. ColEman (ed.), Hart's postscript, New York: Oxford University Press, 39-58.

Evans, G., 1973: «The causal theory of names», Proceedings of the Aristotelian society, Supplementary vol. 47: 187-208.

FERRER BELTRÁN, J., 2010: «Sobre la posibilidad del error judicial y los desacuerdos irrecusables en el derecho. Once comentarios a las tesis de José Juan Moreso», en J. Moreso, L. PriETO SANCHís y J. FERRER BELTRÁN, 2010, Los desacuerdos en el derecho, Madrid: Fundación Coloquio Jurídico Europeo, 147-182.

FERrER BeLtrÁn, J., y RATTI, G., 2011: El realismo jurídico genovés, Barcelona, Marcial Pons.

GuASTINI, R., 2003: Estudios sobre la interpretación jurídica, México: UNAM.

- 2011: «Rule-scepticism restated», en L. GREEN y B. LEITER, Oxford Studies in Philosophy of Law, vol. 1, Oxford: Oxford University Press. En prensa.

Hart, H., 1994: The Concept of Law, 2. ${ }^{\text {a }}$ ed., New York: Oxford University Press. 
Himma, K., 2002: «Ambiguosly stung: Dworkin's semantic sting reconfigured», Legal Theory, 8: $145-183$.

IGLESIAS, M., 1999: El problema de la discreción judicial, Madrid: Centro de Estudios Políticos y Constitucionales.

KRIPKE, S., 1971: «Identity and necessity», en M. K. MunITZ (ed.), Identity and Individuation, New York: New York University Press. Citado por la traducción castellana aparecida en L. M. Valdés Villanueva, 2005, La búsqueda del significado, 4. ${ }^{\text {a }}$ ed., Madrid: Tecnos.

- 1980: Naming and necessity, Cambridge: Harvard University Press.

LEITER, B., 2007: «Explaining Theoretical Disagreements», The Chicago Law School Review, 76, núm. 3, 1215-1250.

MackIE, J., 1977: Ethics. Inventing Right and Wrong, London: Penguin.

Marmor, A., 2005: Interpretation and legal theory, 2. ${ }^{a}$ ed., Oregon: Hart Publishing.

- 2009: Social conventions. From language to law, Oxford: Princeton Monographs in Philosophy.

Montiel, J., y Ramírez, L., 2010: «De camareros estudiantes de biología a jueces biólogos. A propósito de las sentencia del BGH sobre los hongos alucinógenos y la deferencia a los expertos en el ámbito penal», Indret, 1/2010: http://www.indret.com/pdf/691.pdf.

Moore, M., 1987: «Metaphysics, Epistemology and Legal Theory», Southern California Law Review, 60: 453-506. Citado por la versión aparecida en M. MOORE, 2000: Educating oneself in public, New York: Oxford University Press.

Moreso, J. J., 1997: La indeterminación del derecho y la interpretación de la Constitución, Madrid: Centro de Estudios Políticos y Constitucionales.

— 2001: «In Defense of Inclusive Legal Positivism», en P. CHIASSONI (ed.), The Legal Ought, Torino: Giappichelli, 37-63. Citado por la traducción en P. NAVARRO y C. REDONDO (comps.), 2002, La relevancia del derecho, Barcelona: Gedisa.

- 2010a: «La doctrina Julia Roberts y los desacuerdos irrecusables», en J. MorESO, L. PRIETO SANCHís y J. FerRer Beltrán, 2010, Los desacuerdos en el derecho, Madrid: Fundación Coloquio Jurídico Europeo: 49-86.

— 2010b: «Tomates, hongos y significado jurídico», en J. MORESO, L. PRIETO SANChís y J. FeRRER BeLtrán, 2010, Los desacuerdos en el derecho, Madrid: Fundación Coloquio Jurídico Europeo, 15-47.

PapayAnNIS, D., 2010: «El aspecto interpretativo de la regla de reconocimiento». Manuscrito inédito.

Putnam, H., 1973: «Meaning and reference», Journal of philosopby, 70: 699-711. Citado por la traducción castellana aparecida en L. M. VALDÉs VILLANUEVA, 2005: La búsqueda del significado, 4. ${ }^{a}$ ed., Madrid: Tecnos.

- 1975: Mind, Language and Reality: Philosophical Papers, vol. 2, Cambridge: Cambridge University Press.

RATTI, G., 2008: «Los desacuerdos jurídicos en la jurisprudence anglosajona», Analisi e Diritto, 301-331.

RAZ, J., 1979: The authority of law, Oxford: Clarendon Press.

— 1985: «Authority, Law and Morality», Monist, 68: 295-324. Citado por la versión aparecida en J. Raz, 1994, Ethics in the Public Domain, Oxford: Oxford University Press.

- 1994: Ethics in the public domain, Oxford: Clarendon Press.

- 1996: «Intention in interpretation», en R. GEORGE (ed.), The autonomy of Law: Essays on Legal Positivism, Oxford: Clarendon.

- 2001: «Two views of the nature of the theory of law: a partial comparison», en J. COLEMAN (ed.), Hart's postscript, New York: Oxford University Press, 1-37. 
RODRÍGUEZ, J., 2008: «Presentación. En torno a las condiciones de verdad de los enunciados jurídicos», en G. SúCAR, Concepciones del derecho y de la verdad jurídica, Barcelona: Marcial Pons, 11-31.

Rodríguez, J. L., y Perot, P. M., 2010: «Desacuerdos acerca del derecho», Isonomía, 32: 119-147.

SEARLE, J., 1958: «Proper names», Mind, 67: 166-173.

SHAPIRO, S., 1998a: «On Hart's Way Out», Legal Theory, 4: 469-508.

- 1998b: «The Difference That Rules Make», en B. BIX (ed.), Analyzing Law. New Essays in Legal Theory, Oxford: Clarendon Press, 33-64.

— 2007: «The Hart-Dworkin debate: a short guide for the perplexed», en A. RIPSTEIN (ed.), Ronald Dworkin, New York: Cambridge University Press.

- 2011: Legality, Cambridge: Harvard University Press.

Stavropoulos, N., 1996: Objectivity in law, Oxford: Clarendon Press.

Strawson, P. F., 1959: Individuals. An Essay in descriptive Metaphysics, London: Routledge.

VilajosanA, J. M., 2007: Identificación y justificación del derecho, Barcelona: Marcial Pons.

- 2010: El derecho en acción. La dimensión social de las normas jurídicas, Barcelona: Marcial Pons.

WaLuCHOW, W., 1994: Inclusive legal positivism, Oxford: Clarendon Press. 